\title{
Genome-Based Approaches to the Authentication of Medicinal Plants
}

Author

Affiliation
Nikolaus J. Sucher, Maria C. Carles

Centre for Complementary Medicine Research, University of Western Sydney, Penrith South DC, NSW, Australia
Key words

- Medicinal plants

- traditional Chinese medicine

- authentication

- DNA fingerprinting

- genotyping

- plant barcoding received December 18, 2007 revised March 17, 2008 accepted March 19, 2008

\section{Bibliography}

DOI 10.1055/s-2008-1074517 Planta Med 2008; 74: 603-623

(c) Georg Thieme Verlag KG Stuttgart · New York

Published online April 30, 2008

ISSN 0032-0943

\section{Correspondence}

\section{Nikolaus J. Sucher}

Professor of Herbal Pharmacology

The Centre for Complementary Medicine Research

University of Western Sydney

Locked Bag 1797

Penrith South DC

NSW 1797

Australia

Tel.: +61-2-4620-3345

Fax: +61-2-4620-3017

n.sucher@uws.edu.au

\section{Abstract \\ $\nabla$}

Medicinal plants are the source of a large number of essential drugs in Western medicine and are the basis of herbal medicine, which is not only the primary source of health care for most of the world's population living in developing countries but also enjoys growing popularity in developed countries. The increased demand for botanical products is met by an expanding industry and accompanied by calls for assurance of quality, efficacy and safety. Plants used as drugs, dietary supplements and herbal medicines are identified at the species level. Unequivocal identification is a critical step at the beginning of an extensive process of quality assurance and is of importance for the characterization of the genetic diversity, phylogeny and phylogeography as well as the protection of endangered species. DNA-based methods have been developed for the identification of medicinal plants. Nuclear and chloroplast

\section{Introduction \\ $\nabla$}

Plants have been used for medicinal purposes not only by humans since prehistoric times [1], [2] but are also used to treat various ailments by our closest relatives, the African great apes [3], [4]. To date, medicinal plants are the source of a large number of chemical compounds used as drugs in Western medicine and serve as the primary therapeutic resource for most of the world's population living in developing countries [5], [6], [7], [8], [9]. At the same time the use of herbal preparations for health care purposes is gaining popularity in developed countries [10], [11]. The increased demand for botanical products is met by an expanding industry and accompanied by calls for assurance of quality, efficacy and safety [12], [13].
DNA is amplified by the polymerase chain reaction and the reaction products are analyzed by gel electrophoresis, sequencing, or hybridization with species-specific probes. Genomic fingerprinting can differentiate between individuals, species and populations and is useful for the detection of the homogeneity of the samples and presence of adulterants. Although sequences from single chloroplast or nuclear genes have been useful for differentiation of species, phylogenetic studies often require consideration of DNA sequence data from more than one gene or genomic region. Phytochemical and genetic data are correlated but only the latter normally allow for differentiation at the species level. The generation of molecular "barcodes" of medicinal plants will be worth the concerted effort of the medicinal plant research community and contribute to the ongoing effort of defining barcodes for every species on earth.

The botanical sources of herbal supplements and medicines are identified at the species level by their Latin scientific names and the plant species is the basic unit for the preparation of herbal formulations. National pharmacopoeias such as that of China [14] as well as recent drug monographs (e.g., ref. [15]) prepared for the botanical industry and regulators always start their description of herbal drugs by naming the botanical species used for its preparation. Unequivocal identification and authentication of the plants used for production is therefore an elementary and critical step at the beginning of an extensive quality assurance process. Unfortunately, substitution or adulteration either intentionally, e.g., motivated by the desire to maximize financial gains, or unintentionally, e.g., by clerical errors or lack of knowledge, are not rare occurrences [16] and can have tragic consequences [17]. Authentica- 
tion is also of importance for the characterization of the genetic diversity [18], [19], phylogeny and phylogeography [20], [21] as well as the protection and management of endangered species [22].

Identification of plants at the species level is traditionally achieved by careful examination of the specimen's macroscopic and microscopic morphology. This work usually needs to be performed by a specially trained expert. However, morphological identification is often not possible when the original plant material has been processed. Therefore, additional methods of identification at the species level have been sought and genome-based methods have been developed for the identification of medicinal plants starting in the early 1990 s [17], [23]. This work followed in the footsteps of the use of DNA for plant systematics in the preceding two decades [24], [25] and was greatly facilitated by the invention of the polymerase chain reaction (PCR) and the introduction of a heat-stable DNA polymerase from the thermophilic bacterium Thermus aquaticus [26]. Together, these two achievements have revolutionized the way scientists work with DNA and made molecular cloning and DNA-based analysis accessible to workers in virtually every field concerned with living matter. In fact, molecular taxonomists now envision cataloging all living species on earth using so-called DNA barcodes, the nucleotide sequence of a short DNA fragment [27], [28], [29].

Here, we review the published work using genome-based approaches to the authentication of medicinal plants. Much of this work specifically relates to the authentication of plants used as sources of drugs in Chinese medicine. Chinese herbal medicine is part of a system of medical thought and practice that is distinctly different from that of Western medicine [30] and is the most widely practiced form of herbalism worldwide. In recent years, a number of factors have stimulated interest in Chinese medicine in the West, where an increasing number of patients and medical practitioners use herbal medicines as a supplement to or substitute for prescription drugs. Therefore, interactions between herbal and Western medicines have become an important issue in clinical practice [31], [32]. In China and Japan herbal medicines are listed in the national pharmacopoeias and their use is recognized and promoted by official health care policy on equal footing with Western style (single chemical entity) prescription drugs [33], [34], [35], [36].

\section{Molecular Biological Techniques used for Genome-Based Authentication \\ $\nabla$}

An overview and description of the various techniques that have been used for genome-based authentication of medicinal plants is presented in Table 1 . These procedures can be broadly divided into two general approaches. In one approach, investigators determine the nucleotide sequence of one or more genetic loci ("genes") in the plants of interest and identify nucleotide sequences that are characteristic (i.e., inherited by all members) of a given species. Examples of techniques that are based on this approach and are described in 0 Table 2 include allele-specific diagnostic PCR, amplified refractory mutation system (ARMS) and multiplex amplification refractory mutation system (MARMS), DNA microarray, and DNA sequencing. In a second approach, rather than focusing on specific genetic loci, researchers make use of species-specific variations (polymorphisms) of the nucleotide sequence that are spread randomly over the entire genome resulting in characteristic "fingerprints" of genomic
DNA. Examples of techniques that are based on this approach and are described in Table 2 include amplified fragmented length polymorphism (AFLP), arbitrarily primed PCR (AP-PCR), direct amplification of length polymorphism (DALP), randomly amplified polymorphic DNA (RAPD), restriction length polymorphism (RFLP), inter simple sequence repeat anchored PCR and simple sequence repeat polymorphism (SSR). The PCR and its numerous variations are central to both approaches and virtually all of the published genome-based authentication work employs this technique.

PCR was originally developed for the directed amplification of predetermined regions of genomic DNA using primers with a specific sequence and is used in this way for the cloning and sequencing of specific genetic loci. However, PCR can also be used for the amplification of random stretches of DNA using primer pairs with arbitrary nucleotide sequences [37]. With arbitrary primers, the PCR yields a mixture of amplified products (amplicons) of various sizes that can be analyzed by gel electrophoresis. The amplicon patterns reflect the polymorphisms in different genomic DNA samples and are termed RAPD. This version of the PCR is a more rapid and less laborious replacement for the digestion of genomic DNA by restriction enzymes for the characterization of RFLP [38]. Both RAPD and RFLP result in a mixture of DNA fragments. The fragments are sorted by size using gel electrophoresis. The DNA is visualized either directly in the gel using fluorescent dyes (e.g., ethidium bromide) or indirectly using radioactively labeled probes, which are hybridized to the DNA following its transfer ("blotting") from the gel to a solid membrane (e.g., nitrocellulose or nylon). The latter procedure is referred to as Southern blotting using the name of its inventor as an eponym. The pattern obtained with a specific DNA sample is termed its "fingerprint". Once a "fingerprint" has been established for a control sample, the appearance of additional amplicons in test samples signals the presence of impurities or unexpected genetic variation. RAPD was used by some of the early workers using genome-based methods for the authentication of medicinal plants and their RAPD protocols as well as other modified versions of PCR have been collected in a recently published booklet [39]. As a PCR-based procedure, RAPD requires only nanogram amounts of genomic DNA and rapidly and efficiently generates a large number of genomic markers. Although RAPD is suitable for both the rapid sample authentication as well as the assessment of sample purity, it is often not easy to replicate fingerprint patterns established in one laboratory in another because even slight (instrumentation-dependent) variations during the PCR can result in variant fingerprints even when samples of the same genomic DNA are used. In contrast, sequencing will always yield the same result independent of the particular instrumentation used. DNA sequence data can be deposited as simple text strings (with explanatory meta data) in electronic databases such as GenBank and mined easily using text-based bioinformatics tools in contrast to gel-based fingerprints, which will require more complicated image analysis software. Finally, the advent of automated DNA sequencers and DNA microarrays has resulted in a considerable drop in the costs of using these techniques and should favor their more general and widespread use for genome-based authentication of medicinal plants. 
Table 1 Molecular biological methods used for the authentication of medicinal plants

\begin{tabular}{|c|c|c|}
\hline Name & Acronym & Explanation \\
\hline Polymerase chain reaction & PCR & $\begin{array}{l}\text { PCR provides an in vitro method for the rapid enzymatic amplification of fragments of } \\
\text { deoxyribonucleic acid (DNA) [114], [115]. In the PCR procedure, two oligonucleotide } \\
\text { primers (often referred to as "upstream" and "downstream" or "forward" and "re- } \\
\text { verse" primers) that are complementary to the } 5 \text { 'and } 3 \text { ' flanking sequences of the } \\
\text { DNA to be amplified are used to prime a heat-stable DNA polymerase that performs } \\
\text { the copying of each strand of DNA. The denaturation of the DNA double helix, the an- } \\
\text { nealing of the oligonucleotide primers to each complementary strand, and the syn- } \\
\text { thesis of new strands by DNA polymerase are performed at their optimal temperature } \\
\text { resulting in a three-step reaction. PCR is conducted in fully programmable thermocy- } \\
\text { clers that change the reaction temperatures at each step automatically [116]. }\end{array}$ \\
\hline Allele-specific diagnostic PCR & & $\begin{array}{l}\text { Primers with allele specific } 3^{\prime} \text { ends and labeled with different fluorochromes at their } 5^{\prime} \\
\text { end are used together with a common primer in PCR [117]. The resulting amplicons } \\
\text { can be analyzed by gel electrophoresis or capillary electrophoresis using an automa- } \\
\text { ted DNA sequencer. }\end{array}$ \\
\hline Amplification refractory mutation system & ARMS & $\begin{array}{l}\text { This variation of the PCR is based on the fact that the primers only bind to their target } \\
\text { sequence when their } 3^{\prime} \text {-ends are complementary. Oligonucleotides with mismatched } \\
\text { ("mutated") } 3^{\prime} \text { end residues will not bind to the "normal" target sequence and no } \\
\text { amplification will take place [118]. }\end{array}$ \\
\hline Amplified fragmented length polymorphism & AFLP & $\begin{array}{l}\text { In this technique, genomic DNA is digested with restriction enzymes. In a ligation re- } \\
\text { action specific oligonucleotide adapters are added to the ends of the fragments, } \\
\text { which can then be selectively amplified by PCR using primers that are complementary } \\
\text { to the adapter and restriction site sequence [119]. }\end{array}$ \\
\hline Arbitrarily primed PCR & AP-PCR & $\begin{array}{l}\text { Similar to RAPD but PCR is performed using sets of two longer primers (>18 nucleoti- } \\
\text { des) of arbitrary sequence. }\end{array}$ \\
\hline Direct amplification of length polymorphism & DALP & $\begin{array}{l}\text { PCR is conducted with variable forward primers that contain a universal core se- } \\
\text { quence at their } 5^{\prime} \text { end and a constant reverse primer resulting in multiple amplicons } \\
\text { that can be separated by gel electrophoresis, isolated and directly sequenced [120]. }\end{array}$ \\
\hline Multiplex PCR & & $\begin{array}{l}\text { PCR with multiple sets of forward and reverse primers in the same reaction resulting in } \\
\text { parallel amplification [116]. }\end{array}$ \\
\hline PCR-selective restriction & PCR-SR & $\begin{array}{l}\text { PCR amplicons obtained with gene specific primers are cut with restriction enzymes } \\
\text { and analyzed by gel electrophoresis [121]. }\end{array}$ \\
\hline Randomly amplified polymorphic DNA & RAPD & $\begin{array}{l}\text { Genomic DNA (gDNA) is amplified by PCR using a single, short ( } 10 \text { nucleotides) primer } \\
\text { with arbitrary sequence resulting in multiple amplicons of different lengths ("finger- } \\
\text { print" pattern) that are analyzed by gel electrophoresis [37]. }\end{array}$ \\
\hline Sequence characterized amplified region & SCAR & $\begin{array}{l}\text { Distinct amplicons obtained by RAPD are sequenced and amplicon specific primers } \\
\text { are designed for use in PCR [122]. }\end{array}$ \\
\hline Restriction length polymorphism & RFLP & $\begin{array}{l}\text { Genomic DNA is cut with sequence specific DNA restriction endonucleases resulting } \\
\text { in the generation of a number of small fragments of various lengths, which are sepa- } \\
\text { rated according to their molecular size by gel electrophoresis. The band pattern ob- } \\
\text { tained with a specific DNA source and a specific restriction enzyme is called a DNA } \\
\text { fingerprint of that source. }\end{array}$ \\
\hline DNA microarray & & $\begin{array}{l}\text { A DNA microarrays, also often referred to as gene chip, DNA chip, or gene array, con- } \\
\text { sists of a solid support matrix (e. g. a glass slide, silicon chip or synthetic membrane) } \\
\text { to which DNA has been covalently bound in the form of a collection of microscopic } \\
\text { spots [123]. Each spot contains DNA of a defined sequence that is referred to as the } \\
\text { probe. Fluorescently labeled target DNA is hybridized to the chip, which is washed and } \\
\text { then analyzed using a microarray reader. }\end{array}$ \\
\hline DNA sequencing & & $\begin{array}{l}\text { DNA sequencing is now almost exclusively performed using cycle sequencing, which } \\
\text { is conducted using a heat stable DNA polymerase and fluorescently labeled dideoxy- } \\
\text { nucleotides in a thermocyler. The resulting polymerase products are separated ac- } \\
\text { cording to length using capillary electrophoresis, detected by laser-induced fluores- } \\
\text { cence and automatically analyzed by computer software [124]. Older methods mak- } \\
\text { ing use of radioactively labeled nucleotides and gel electrophoresis are still in use and } \\
\text { may be the only option, when access to automated sequencers is not available. }\end{array}$ \\
\hline Inter simple sequence repeat-anchored PCR & ISSR-PCR & $\begin{array}{l}\text { In ISSR-PCR, primers anchored at simple sequence repeat (SSR) sequences (e. g., } \\
\text { CACACACA; see below) are used to amplify the DNA regions between the flanking SSR } \\
\text { [125]. }\end{array}$ \\
\hline $\begin{array}{l}\text { Multiplex amplification refractory mutation } \\
\text { system }\end{array}$ & MARMS & $\begin{array}{l}\text { Multiplex PCR using a common primer and multiple mutation specific primers as used } \\
\text { in ARMS [126]. }\end{array}$ \\
\hline Simple sequence repeat polymorphism & SSR & $\begin{array}{l}\text { Simple sequence repeats (SSRs) or microsatellites are short sequence motifs consist- } \\
\text { ing of } 2 \text { or more nucleotides (e. g., CA and ATG), which repeat in tandem (e. g., CACA- } \\
\text { CA and ATGATGATG). The repeats vary in length (e. g., CACACA vs. CACACACACACA) } \\
\text { and are ubiquitously and randomly distributed in all eukaryotic genomes. The length- } \\
\text { polymorphisms can be easily detected by gel electrophoresis of amplicons generated } \\
\text { by PCR using unique pairs of primers flanking the repeat [127]. }\end{array}$ \\
\hline
\end{tabular}


Table 2 Nuclear and chloroplast genes used for authentication of medicinal plants

\begin{tabular}{|c|c|c|}
\hline Gene & Genome & Explanantion \\
\hline 18S rRNA & Nuclear & $\begin{array}{l}\text { The } 18 \mathrm{~S} \text { ribosomal ribonucleic acid (rRNA) sequences have been widely used for phy- } \\
\text { logenetic studies in plants [128]. }\end{array}$ \\
\hline $\begin{array}{l}\text { Internal transcribed spacers (ITS) of } 18 \mathrm{~S} \text {, } \\
5.8 \mathrm{~S} \text { and } 26 \mathrm{~S} \text { rRNA }\end{array}$ & Nuclear & $\begin{array}{l}\text { In land plants, the } 18 \mathrm{~S}, 5.8 \mathrm{~S} \text { and } 26 \mathrm{~S} \text { rRNA genes form a linearly arrayed unit (a cistron) } \\
\text { in which the individual coding regions separated by } 2 \text { internal transcribed spacers } \\
\text { (ITS; ITS } 1 \text { between the } 18 \mathrm{~S} \text { and } 5.8 \mathrm{~S} \text { genes and ITS } 2 \text { between } 5.8 \mathrm{~S} \text { and } 26 \mathrm{~S} \text { genes). The } \\
\text { cistron itself is tandemly arrayed separated by external transcribed spacers (ETS) on } \\
\text { one or more chromosomes [57], [60], [129]. The ITS region has been used in many } \\
\text { phylogenetic studies [58]. }\end{array}$ \\
\hline $\begin{array}{l}\text { Intergenic spacer of the } 5 S \text { rRNA } \\
\text { ( } 5 \text { S gene spacer) }\end{array}$ & Nuclear & $\begin{array}{l}\text { In land plants, the genes for the } 5 \mathrm{~S} \text { ribosomal RNA (rRNA) are arrayed as tandem re- } \\
\text { peats separated by intergenic spacers on one or more chromosomes [57]. The } 5 \mathrm{~S} \\
\text { rRNA sequence has been used for construction of the phylogenetic tree of major or- } \\
\text { ganisms [61]. }\end{array}$ \\
\hline $26 S$ rRNA & Nuclear & $\begin{array}{l}\text { The entire coding region of the } 26 S \text { rRNA gene can be amplified by DNA and was re- } \\
\text { ported to provide } ~ 3 \text { times more phylogenetically informative characters than the } \\
18 \text { rRNA. The } 26 S \text { rRNA sequence consists of conserved core and highly variable ex- } \\
\text { pansion regions [128]. }\end{array}$ \\
\hline atpA, atpB, atpF, atpH & Chloroplast & $\begin{array}{l}\text { Single copy chloroplast genes coding for the ATP synthase subunits } \alpha \text { (atpA), } \beta \text { (atpB), } \\
\text { I (atpF), and } \delta(\operatorname{atpH}) \text { ), res [130]. }\end{array}$ \\
\hline chlB & Chloroplast & $\begin{array}{l}\text { A chloroplast gene coding for a subunit of the light-independent protochlorophyllide } \\
\text { reductase that catalyzes the reduction of protochlorophyllide to chlorophyllide in } \\
\text { photosynthetic bacteria, algae, and gymnosperms but is not present in angiosperms } \\
\text { [131]. }\end{array}$ \\
\hline matK & Chloroplast & $\begin{array}{l}\text { The matK gene, which is located within the trnK intron and comprises } ~ 1.6 \mathrm{kbp} \text {. It is } \\
\text { assumed to be involved in the splicing of group II introns [132]. }\end{array}$ \\
\hline psbA, psbK, psbl & Chloroplast & The pbs genes code for proteins of photosystem II. \\
\hline rbcl & Chloroplast & $\begin{array}{l}\text { Large subunit of the enzyme ribulose-1,5-biphosphate carboxylase }(\mathrm{rbcL}) \text { is one of the } \\
\text { largest ( } 1.4 \mathrm{kbp}) \text { genes in the chloroplast genome. It has been sequenced in a large } \\
\text { number of plants beginning in the mid-1980s [55], [56]. }\end{array}$ \\
\hline гр14, гpl16 & Chloroplast & $\begin{array}{l}\text { Chloroplast genes coding for the ribosomal proteins L14 and L16, constituents of the } \\
\text { large subunit (50S) of the chloroplast ribosome. The chloroplast ( } 70 S) \text { and nuclear } \\
(80 S) \text { ribosomes are of different size [130]. }\end{array}$ \\
\hline гров, гроС1 & Chloroplast & $\begin{array}{l}\text { Chloroplast gene coding for DNA-directed RNA polymerase beta and gamma chains, } \\
\text { respectively. }\end{array}$ \\
\hline rps16 & Chloroplast & $\begin{array}{l}\text { Chloroplast gene coding for the ribosomal proteins S16, a constituent of the small } \\
\text { subunit of the chloroplast ribosome. }\end{array}$ \\
\hline $\operatorname{trnC}, \operatorname{trn} D, \operatorname{trn} F, \operatorname{trnK}, \operatorname{trnL}$ & Chloroplast & $\begin{array}{l}\text { Genes coding for the transfer RNA (tRNA) for cystein, aspartate, phenylalanine, lysine, } \\
\text { and leucine, respectively. Chloroplast genomes code for } 20 \text { to } 40 \text { different tRNAs } \\
\text { [130]. Regions used in molecular taxonomy include the trnL intron and various tRNA } \\
\text { intergenic spacer regions [133]. }\end{array}$ \\
\hline
\end{tabular}

\section{Microchip-Based Authentication of Medicinal Plants \\ $\nabla$}

The desire to speed up the often slow and labor-intensive molecular analyses and reduce costs, has driven research and engineering efforts aimed at the automation and miniaturization of molecular biological analytical techniques and the development of miniature chip-based analytical devices with the goal to build a "lab-on-a-chip" [40], [41], [42], [43]. Our own work in this regard has been aimed at the development of microchip-based devices integrating sample preparation, amplification, detection, and analysis for the DNA-based identification of traditional Chinese herbal materials [44], [45], [46], [47], [48]. We chose silicon as primary and glass as secondary substrates for the fabrication of these devices. Silicon, the paramount substrate for the fabrication of electronic microchips, also offers a number of important advantages for the fabrication of lab-on-a-chip devices and we have recently shown that commonly used microfabrication techniques used in the production of electronic circuits can be modified to include biological materials such as DNA and even protein [49]. Using microfabrication methods, we built silicon- based microchips integrating PCR reactors with built-in electrochemical detection or DNA microarrays and demonstrated their use for the genotyping of Chinese medicinal plants [46], [47]. This work demonstrated that the chips are suitable for the use in the design of automated systems for industrial use and even battery-operated, hand-held devices used as mobile instrumentation in the field.

\section{Molecular Basis of Genome-Based Authentication $\nabla$}

Plant DNA comprises three independently replicated genomes. In addition to the nuclear genome that is organized in chromosomes, plants contain circular chloroplast and mitochondrial genomes. The nuclear DNA content (C-value) varies approximately 1000 -fold across the angiosperms but exact C-values based on genome sequencing have not been obtained for any angiosperm to date [50]. The chloroplast genome in angiosperms ranges in size between 120 and $220 \mathrm{~kb}$ [51] and the plant mitochondrial genome varies in size from $200 \mathrm{~kb}$ in Brassica to over $2.5 \mathrm{Mb}$ in watermelon and is substantially larger than that in animals, 
which is only between $15-18 \mathrm{~kb}$ [52]. Interestingly, "whole" genome size determined by sequencing is generally smaller than the $\mathrm{C}$-values indicate, as considerable amounts of genomic DNA cannot be cloned and sequenced with currently available techniques [50]. For example, the Arabidopsis Genome Initiative estimated the "genome" size of Arabidopsis thaliana at $\sim 25 \mathrm{Mb}$ (115.4 Mb in the sequenced regions plus an estimated $10 \mathrm{Mb}$ in unsequenced regions) but recent data indicate that it may be considerably larger at $157 \mathrm{Mb}$ [50].

The use of genome-based methods for the authentication of medicinal plants should be seen in the context of plant phylogenetic studies and a general effort aimed at barcoding of all plants [53], [54], [55], [56], [57]. Genetic loci commonly used for the authentication of medicinal plants have included the internal transcribed spacers (ITS) that separate the coding regions of the nuclear 5.8S, $18 \mathrm{~S}$ and 26S rRNA genes [58], [59], [60] and the intergenic spacers that separate multiple repeated copies of the nuclear $5 \mathrm{~S}$ rRNA gene [61]. On the other hand, genetic loci used in phylogenetic studies include several chloroplast-based genes [55], [56] such as atpF, matK, rbcL, rpoB, and rpoC1, the trnL intron and intergenic spacers between the trnC-trnD, trnL-trnF, $\operatorname{trn} H-p s b A$, and psbK-psbKI genes. It is noteworthy that the ITS and 5S spacers have been found to lack sufficient discriminatory power in some phylogenetic studies. In fact, sequence data from a single gene have proved to be insufficient for barcoding purposes in plants because multiple closely related species have been found to possess identical sequences at some loci. Consequently, the consensus view has developed that the unequivocal identification and barcoding of all plant species will require consideration of sequence data from more than one locus [53], [54], [62]. The generation of molecular "barcodes" of medicinal plants and deposition of sequence data in publicly accessible databases will be worth the concerted effort of the medicinal plant research community and contribute to the ongoing effort of defining barcodes for every (plant) species on earth. Along these lines, future studies aimed at the authentication of medicinal plants using genomic methods should focus on genetic loci that have been found useful for barcoding of plants in general in addition to those previously described in the literature.

\section{Application of Genome-Based Authentication}

An overview of work that has been performed for the genomebased authentication of medicinal plants is presented in $\odot$ Table 3, which collates information from 82 published papers. The columns of the Table contain (from left to right): 1) an alphabetical list of the scientific names of the medicinal plant species that have been investigated (Plant) with information on 2) the plant parts (e.g., leave or root; Part) used for DNA extraction and 3) their condition (e.g., fresh or dry; Condition), an indication of whether 4) a voucher specimen was retained (Voucher), 5) the method (e.g., DNA sequencing; Method), 6) the genetic loci used (Gene) and 7) the number corresponding to the original paper in the list of references (Ref).

Species that have been investigated using genome-based methods for authentication include plants of economical importance such as Panax [17], [63], [64], [65], [66], [67], [68], [69], [70], [71], [72], [73], [74], [75], Fritillaria [76], [77], [78], [79], [80], and Ephedra [81], [82], [83], [84], [85]. Published work furthermore includes species of forensic importance such as Cannabis [86], [87], [88], species threatened by extinction such as the wild orchid Dendrobium [89], [90], [91], [92], [93], [94], [95], [96], [97], [98], [99], [100], [101], species of unclear phylogenetic relationship such as Astragalus [20], [102], [103], [104], [105], [106], and various toxic species such as Aconitum, Datura and Strychnos [44]. The data show that DNA was generally isolated from fresh leaves, stems or roots but in some cases also from dried material, crude drug, extracts and even finished products such as herbal teas, tablets and capsules [85]. Most of the studies included morphological identification of the plants by experts and deposition of voucher specimens in herbaria and museums. Availability of voucher specimens is useful in case potential discrepancies between past and future studies need to be resolved. A large number of studies have used PCR to establish genetic markers for the authentication of medicinal plants and detection of adulterants. The PCR is one of the most sensitive analytical techniques available and using carefully optimized conditions, it can be used to detect the presence of a single template molecule. In practice, however, pushing the limit of detection is prone to contamination artifacts. Therefore, it is better to use sufficient amounts of good quality template DNA that is free of PCR-inhibiting contaminants than to carry out PCR with a high number of amplification cycles (>35). The best method for the extraction and purification of DNA from a particular plant or drug sample needs to be established empirically. Techen and colleagues [85] showed that the success of PCR was dependent on both the type of source material (raw plants, herbal teas, tablets, capsules) as well as the specific brand of commercial DNA extraction kit used. Following optimization of extraction and PCR, these workers reported correct identification of Ephedra species in complex herbal mixtures containing as little as 1:1000 part Ephedra tissue [85].

Several investigations examined the correlation of genetic markers with intra- and interspecies geographical and phytochemical variation. For example, workers using the DNA sequence of the 5S rRNA intergenic spacer domain as species identifier found both intra- and interspecies differences in the phytochemical fingerprints established by HPLC [105], [107], [108]. However, only DNA data could resolve species level differences in Rehmannia [18]. Not surprisingly, whole-genome RAPD or APPCR patterns exhibited more variation at the species level than the sequences of single DNA regions. For example, samples of Astragalus membranaceus collected from different geographical regions in China exhibited identical ITS1 sequences but different AP-PCR fingerprints [105]. Similarly, AP-PCR or RAPD fingerprints differentiated samples of Codonopsis pilosula from different regions in China [109]. Fruits from Vitex rotundifolia obtained from 14 different locations in China could be divided into four closely matching groups based on chemical fingerprinting using HPLC and DNA fingerprinting based on inter simple sequence repeat (ISSR)-anchored PCR [19]. Roots of Panax notoginseng collected from a single farm exhibited variation in their AFLP fingerprints which correlated with morphological differences such as variations in leaf color and phytochemical differences such as saponin content [67]. On the other hand, a study of cultivated Ephedra plants from different regions in China revealed not only the presence of both Ephedra sinica and Ephedra intermedia in the same field but also the occurrence of plants with markers for either species and varied morphology [83]. Dong and colleagues determined the DNA sequences of the $5 \mathrm{~S}$ rRNA spacer, ITS and the $18 \mathrm{~S}$ rRNA coding region in 10 different taxa of Astragalus and used several different bioinformatics tools to construct phylogenetic trees with each genetic region 
Table 3 Quick reference to publications on the application of genome-based methods for the authentication of medicinal plants sorted by species and quick references to experimental methods used (blank = no information provided)

\begin{tabular}{|c|c|c|c|c|c|c|}
\hline $\begin{array}{l}\text { Plant } \\
\text { (scientific name) }\end{array}$ & Part & Condition & Voucher & Method & Gene & Ref \\
\hline Aconitum carmichaeli & Leaves & Fresh & Yes & $\begin{array}{l}\text { PCR, sequencing; microarray } \\
\text { (silicon) }\end{array}$ & $5 S$ gene spacer & [44] \\
\hline Aconitum napellus & Leaves & & Yes & AFLP & N/A (not applicable) & [134] \\
\hline Aconitum pendulum & & & & $\begin{array}{l}\text { PCR, sequencing; microarray } \\
\text { (silicon) }\end{array}$ & $\operatorname{trnL}$ & [44] \\
\hline Actaea racemosa & Leaves & & Yes & AFLP & N/A & [134] \\
\hline Actaea cordifolia & Leaves & & Yes & AFLP & $\mathrm{N} / \mathrm{A}$ & [134] \\
\hline Actaea podocarpa & Leaves & & Yes & AFLP & $\mathrm{N} / \mathrm{A}$ & [134] \\
\hline Actaea pachypoda & Leaves & & Yes & AFLP & N/A & [134] \\
\hline $\begin{array}{l}\text { Adenophora } \\
\text { hunanensis }\end{array}$ & & Fresh, crude drug & Yes & $\mathrm{PCR}$, sequencing & $5 \mathrm{~S}$ gene spacer & [135] \\
\hline Adenophora stricta & & Fresh, crude drug & Yes & PCR, sequencing & $5 S$ gene spacer & [135] \\
\hline $\begin{array}{l}\text { Adenophora } \\
\text { tetraphylla }\end{array}$ & & Fresh, crude drug & Yes & PCR, sequencing & $5 S$ gene spacer & [135] \\
\hline Agastache foeniculum & & & Yes & $\mathrm{PCR}$, sequencing & 18S rRNA; matK & [136] \\
\hline Agastache rugosa & & & Yes & PCR, sequencing & 18S rRNA; matK & [136] \\
\hline Alisma canaliculatum & Rhizome & Dried & Yes & PCR, sequencing; RFLP; ARMS & ITS & [137] \\
\hline Alisma gramineum & Rhizome & Dried & Yes & PCR, sequencing; RFLP; ARMS & ITS & [137] \\
\hline Alisma lanceolatum & Rhizome & Dried & Yes & PCR, sequencing; RFLP; ARMS & ITS & [137] \\
\hline Alisma nanum & Rhizome & Dried & Yes & PCR, sequencing; RFLP; ARMS & ITS & [137] \\
\hline Alisma orientale & Rhizome & Dried & Yes & PCR, sequencing; RFLP; ARMS & ITS & [137] \\
\hline $\begin{array}{l}\text { Alisma } \\
\text { plantago-aquatica }\end{array}$ & Rhizome & Dried & Yes & PCR, sequencing; RFLP; ARMS & ITS & [137] \\
\hline Alocasia macrorrhiza & Leaves & Fresh & Yes & $\begin{array}{l}\text { PCR, sequencing; microarray } \\
\text { (silicon) }\end{array}$ & $5 S$ gene spacer & [44] \\
\hline Angelica acutiloba & & Dried & Yes & PCR, sequencing & $5 S$ gene spacer & [107] \\
\hline $\begin{array}{l}\text { Angelica acutiloba var. } \\
\text { acutiloba }\end{array}$ & Leaves & Fresh & & $\mathrm{PCR}$, sequencing & $\begin{array}{l}\text { Spacer between } \\
\text { atpF-atpA }\end{array}$ & [138] \\
\hline $\begin{array}{l}\text { Angelica acutiloba var. } \\
\text { iwatensis }\end{array}$ & Leaves & Fresh & & $\mathrm{PCR}$, sequencing & $\begin{array}{l}\text { Spacer between } \\
\text { atpF-atpA }\end{array}$ & [138] \\
\hline $\begin{array}{l}\text { Angelica acutiloba var. } \\
\text { sugijamae }\end{array}$ & Leaves & Fresh & & $\mathrm{PCR}$, sequencing & $\begin{array}{l}\text { Spacer between } \\
\text { atpF-atpA }\end{array}$ & [138] \\
\hline Angelica acutiloba & Leaves & Fresh & & RAPD; RFLP & N/A & [139] \\
\hline $\begin{array}{l}\text { Angelica acutiloba var. } \\
\text { Sugiyamae }\end{array}$ & Leaves & Fresh & & RAPD; RFLP & $\mathrm{N} / \mathrm{A}$ & [139] \\
\hline Angelica gigas & & Dried & Yes & PCR, sequencing & $5 S$ gene spacer & [107] \\
\hline Angelica sinensis & & Dried & Yes & $\mathrm{PCR}$, sequencing & $5 \mathrm{~S}$ gene spacer & [107] \\
\hline Angelica sinensis & Root & Dried & & RAPD; RFLP & N/A & [139] \\
\hline Aralia elata & & & Yes & PCR, sequencing & ITS; trnC-trnD & [69] \\
\hline Aralia franchetii & & & Yes & PCR, sequencing & ITS; trnC-trnD & [69] \\
\hline $\begin{array}{l}\text { Arisaema } \\
\text { heterophyllum }\end{array}$ & Leaves & Fresh & Yes & PCR, sequencing; PCR-SR & $\begin{array}{l}\text { Mannose-binding } \\
\text { lectin }\end{array}$ & [121] \\
\hline Artemisia aponica & Leaves & Fresh & & PCR, sequencing, SCAR & $\mathrm{N} / \mathrm{A}$ & [140] \\
\hline Artemisia argyi & Leaves & Fresh & & PCR, sequencing, SCAR & $\mathrm{N} / \mathrm{A}$ & [140] \\
\hline Artemisia capillaries & Leaves & Fresh & & PCR, sequencing, SCAR & $\mathrm{N} / \mathrm{A}$ & {$[140]$} \\
\hline Artemisia iwayomogi & Leaves & Fresh & & PCR, sequencing, SCAR & $\mathrm{N} / \mathrm{A}$ & {$[140]$} \\
\hline Artemisia keiskeana & Leaves & Fresh & & PCR, sequencing, SCAR & $\mathrm{N} / \mathrm{A}$ & [140] \\
\hline Artemisia princes & Leaves & Fresh & & PCR, sequencing, SCAR & $\mathrm{N} / \mathrm{A}$ & [140] \\
\hline Asarum arifolium & & & Yes & PCR, sequencing & ITS & [141] \\
\hline Asarum asaroides & & & Yes & $\mathrm{PCR}$, sequencing & ITS & [141] \\
\hline Asarum asperum & & & Yes & $\mathrm{PCR}$, sequencing & ITS & [141] \\
\hline Asarum blumei & & & Yes & PCR, sequencing & ITS & [141] \\
\hline Asarum canadense & & & Yes & $\mathrm{PCR}$, sequencing & ITS & [141] \\
\hline Asarum caudatum & & & Yes & $\mathrm{PCR}$, sequencing & ITS & [141] \\
\hline $\begin{array}{l}\text { Asarum } \\
\text { caudigerellum }\end{array}$ & & & Yes & $\mathrm{PCR}$, sequencing & ITS & [141] \\
\hline Asarum caudigerum & & & Yes & $\mathrm{PCR}$, sequencing & ITS & [141] \\
\hline Asarum caulescens & & & Yes & PCR, sequencing & ITS & [141] \\
\hline Asarum crassum & & & Yes & $\mathrm{PCR}$, sequencing & ITS & [141] \\
\hline Asarum debile & & & Yes & $\mathrm{PCR}$, sequencing & ITS & [141] \\
\hline Asarum dimidiatum & & & Yes & PCR, sequencing & ITS & [21] \\
\hline Asarum europaeum & & & Yes & PCR, sequencing & ITS & [141] \\
\hline
\end{tabular}




\begin{tabular}{|c|c|c|c|c|c|c|}
\hline $\begin{array}{l}\text { Plant } \\
\text { (scientific name) }\end{array}$ & Part & Condition & Voucher & Method & Gene & Ref \\
\hline Asarum forbesii & & & Yes & $\mathrm{PCR}$, sequencing & ITS & {$[141]$} \\
\hline Asarum fudsinoi & & & Yes & $\mathrm{PCR}$, sequencing & ITS & [141] \\
\hline Asarum gelasinum & & & Yes & PCR, sequencing & ITS & [141] \\
\hline Asarum hartwegii & & & Yes & $\mathrm{PCR}$, sequencing & ITS & [141] \\
\hline Asarum hatsushimae & & & Yes & PCR, sequencing & ITS & [141] \\
\hline $\begin{array}{l}\text { Asarum } \\
\text { heterotropoides var. } \\
\text { heterotropoides }\end{array}$ & & & Yes & $\mathrm{PCR}$, sequencing & ITS & {$[21]$} \\
\hline $\begin{array}{l}\text { Asarum } \\
\text { heterotropoides var. } \\
\text { mandshuricum }\end{array}$ & & & & PCR, sequencing & ITS & {$[142]$} \\
\hline $\begin{array}{l}\text { Asarum } \\
\text { heterotropoides var. } \\
\text { mandshuricum }\end{array}$ & & & Yes & PCR, sequencing & ITS & [21] \\
\hline $\begin{array}{l}\text { Asarum heterotro- } \\
\text { poides var. seoulense }\end{array}$ & & & Yes & PCR, sequencing & ITS & {$[21]$} \\
\hline Asarum himalaicum & & & Yes & PCR, sequencing & ITS & {$[141]$} \\
\hline Asarum lemonii & & & Yes & PCR, sequencing & ITS & {$[141]$} \\
\hline Asarum marmoratum & & & Yes & $\mathrm{PCR}$, sequencing & ITS & [141] \\
\hline Asarum maruyamae & & & Yes & $\mathrm{PCR}$, sequencing & ITS & [21] \\
\hline Asarum mikuniense & & & Yes & $\mathrm{PCR}$, sequencing & ITS & [21] \\
\hline $\begin{array}{l}\text { Asarum } \\
\text { minimitanianum }\end{array}$ & & & Yes & PCR, sequencing & ITS & [141] \\
\hline Asarum minor & & & Yes & $\mathrm{PCR}$, sequencing & ITS & {$[141]$} \\
\hline Asarum misandrum & & & Yes & $\mathrm{PCR}$, sequencing & ITS & [21] \\
\hline Asarum patens & & & Yes & PCR, sequencing & ITS & [21] \\
\hline Asarum pulchellum & & & Yes & $\mathrm{PCR}$, sequencing & ITS & [141] \\
\hline Asarum satsumense & & & Yes & PCR, sequencing & ITS & [141] \\
\hline Asarum savatieri & & & Yes & $\mathrm{PCR}$, sequencing & ITS & [141] \\
\hline $\begin{array}{l}\text { Asarum } \\
\text { shuttleworthii }\end{array}$ & & & Yes & PCR, sequencing & ITS & [141] \\
\hline Asarum sieboldii & & & & PCR, sequencing & ITS & {$[142]$} \\
\hline Asarum sieboldii & & & Yes & PCR, sequencing & ITS & {$[141]$} \\
\hline $\begin{array}{l}\text { Asarum sieboldiif. } \\
\text { maculatum }\end{array}$ & & & Yes & PCR, sequencing & ITS & [21] \\
\hline $\begin{array}{l}\text { Asarum sieboldiif. } \\
\text { seoulense }\end{array}$ & & & & $\mathrm{PCR}$, sequencing & ITS & {$[142]$} \\
\hline $\begin{array}{l}\text { Asarum sieboldiif. } \\
\text { siboldii }\end{array}$ & & & Yes & $\mathrm{PCR}$, sequencing & ITS & [21] \\
\hline $\begin{array}{l}\text { Asarum sieboldii var. } \\
\text { cornutum }\end{array}$ & & & Yes & $\mathrm{PCR}$, sequencing & ITS & [21] \\
\hline Asarum speciosum & & & Yes & PCR, sequencing & ITS & {$[141]$} \\
\hline Asarum takaoi & & & Yes & PCR, sequencing & ITS & [141] \\
\hline Asarum tohokuense & & & Yes & $\mathrm{PCR}$, sequencing & ITS & [21] \\
\hline Asarum versicolor & & & Yes & $\mathrm{PCR}$, sequencing & ITS & [21] \\
\hline Asarum virginicum & & & Yes & $\mathrm{PCR}$, sequencing & ITS & [141] \\
\hline Asarum yakusimense & & & Yes & PCR, sequencing & ITS & [141] \\
\hline Astragalus aksuensis & & Dried & Yes & $\mathrm{PCR}$, sequencing & $\begin{array}{l}\text { 5S gene spacer, ITS; } \\
\text { 18S rRNA }\end{array}$ & [20] \\
\hline $\begin{array}{l}\text { Astragalus } \\
\text { austrosibiricus }\end{array}$ & & Dried & Yes & $P C R$, sequencing & $\begin{array}{l}\text { 5S gene spacer; ITS; } \\
\text { 18S rRNA }\end{array}$ & {$[20]$} \\
\hline Astragalus hoantchy & & Dried & Yes & PCR, sequencing & $\begin{array}{l}\text { 5S gene spacer; ITS; } \\
\text { 18S rRNA }\end{array}$ & {$[20]$} \\
\hline $\begin{array}{l}\text { Astragalus hoantchy } \\
\text { subsp. Dshimensis }\end{array}$ & & Dried & Yes & $\mathrm{PCR}$, sequencing & $\begin{array}{l}\text { 5S gene spacer; ITA; } \\
\text { 18S rRNA }\end{array}$ & {$[20]$} \\
\hline $\begin{array}{l}\text { Astragalus } \\
\text { lehmannianus }\end{array}$ & Leaves, roots & Fresh, crude drug & Yes & $\mathrm{PCR}$, sequencing & $5 \mathrm{~S}$ gene spacer & [104] \\
\hline $\begin{array}{l}\text { Astragalus } \\
\text { lehmannianus }\end{array}$ & & Dried & Yes & $\mathrm{PCR}$, sequencing & $\begin{array}{l}\text { 5S gene spacer; ITS; } \\
\text { 18S rRNA }\end{array}$ & {$[20]$} \\
\hline Astragalus lepsensis & & Dried & Yes & PCR, sequencing & $\begin{array}{l}\text { 5S gene spacer; ITS; } \\
\text { 18S rRNA }\end{array}$ & {$[20]$} \\
\hline \multirow{2}{*}{$\begin{array}{l}\text { Astragalus } \\
\text { membranaceus }\end{array}$} & Leaves, roots & Fresh, crude drug & Yes & $\mathrm{PCR}$, sequencing & $5 \mathrm{~S}$ gene spacer & {$[104]$} \\
\hline & & Dried & Yes & PCR, sequencing & $\begin{array}{l}\text { 5S gene spacer; ITS; } \\
\text { 18S rRNA }\end{array}$ & [20] \\
\hline
\end{tabular}




\begin{tabular}{|c|c|c|c|c|c|c|}
\hline Plant & Part & Condition & Voucher & Method & Gene & Ref \\
\hline & Roots & Fresh & & $\begin{array}{l}\text { 3'untranslated region } \\
\text { sequence-based amplified } \\
\text { polymorphism (UAP) }\end{array}$ & $\begin{array}{l}3^{\prime} \text { untranslated } \\
\text { regions (3'UTR) }\end{array}$ & [102] \\
\hline & & & & RAPD & $\mathrm{N} / \mathrm{A}$ & [106] \\
\hline $\begin{array}{l}\text { Astragalus } \\
\text { membranaceus from } \\
23 \text { locations }\end{array}$ & & Dried & & AP-PCR & ITS & [105] \\
\hline \multirow{3}{*}{$\begin{array}{l}\text { Astragalus } \\
\text { membranaceus var. } \\
\text { mongholicus }\end{array}$} & Leaves, roots & Fresh, crude drug & Yes & $\mathrm{PCR}$, sequencing & $5 S$ gene spacer & [104] \\
\hline & & Dried & Yes & $\mathrm{PCR}$, sequencing & $\begin{array}{l}\text { 5S gene spacer; ITS; } \\
\text { 18S rRNA }\end{array}$ & [20] \\
\hline & Roots & Fresh & & $\begin{array}{l}\text { 3'untranslated region } \\
\text { sequence-based amplified } \\
\text { polymorphism (UAP) }\end{array}$ & $\begin{array}{l}3^{\prime} \text { untranslated } \\
\text { regions (3'UTR) }\end{array}$ & [102] \\
\hline $\begin{array}{l}\text { Astragalus } \\
\text { membranaceus var. } \\
\text { mongholicus from } 23 \\
\text { locations }\end{array}$ & & Dried & & AP-PCR & ITS & [105] \\
\hline $\begin{array}{l}\text { Astragalus } \\
\text { propinquus }\end{array}$ & & Dried & Yes & $\mathrm{PCR}$, sequencing & $\begin{array}{l}\text { 5S gene spacer; ITS; } \\
\text { 18S rRNA }\end{array}$ & [20] \\
\hline $\begin{array}{l}\text { Astragalus } \\
\text { sieversianus }\end{array}$ & & Dried & Yes & $\mathrm{PCR}$, sequencing & $\begin{array}{l}\text { 5S gene spacer; ITS; } \\
\text { 18S rRNA }\end{array}$ & [20] \\
\hline Astraglus hoantchy & Leaves, roots & Fresh, crude drug & Yes & $\mathrm{PCR}$, sequencing & $5 \mathrm{~S}$ gene spacer & [104] \\
\hline $\begin{array}{l}\text { Atractylodes } \\
\text { chinensis }\end{array}$ & Crude drug & & & $\mathrm{PCR}$, sequencing & ITS & [143] \\
\hline Atractylodes japonica & & & & RAPD & $\mathrm{N} / \mathrm{A}$ & [144] \\
\hline Atractylodes japonica & Crude drug & & & PCR, sequencing & ITS & [143] \\
\hline Atractylodes lancea & & & & RAPD & $\mathrm{N} / \mathrm{A}$ & [144] \\
\hline Atractylodes lancea & Leaves & Fresh & & PCR, sequencing, SCAR & N/A & [140] \\
\hline Atractylodes ovata & & & & RAPD & $\mathrm{N} / \mathrm{A}$ & [144] \\
\hline Atractylodes ovata & Crude drug & & & PCR, sequencing & ITS & [143] \\
\hline Bacopa monnieri & Leaves & Fresh & & RAPD & $\mathrm{N} / \mathrm{A}$ & [145] \\
\hline Bupleurum aureum & & Fresh & & $\mathrm{PCR}$, sequencing & ITS & [146] \\
\hline Bupleurum chinense & & Fresh & & $\mathrm{PCR}$, sequencing & ITS & [146] \\
\hline $\begin{array}{l}\text { Bupleurum } \\
\text { commelynoideium var. } \\
\text { flaviflorum }\end{array}$ & & Fresh & & PCR, sequencing & ITS & [146] \\
\hline $\begin{array}{l}\text { Bupleurum } \\
\text { krylovianum }\end{array}$ & & Fresh & & $\mathrm{PCR}$, sequencing & ITS & [146] \\
\hline $\begin{array}{l}\text { Bupleurum } \\
\text { longiradiatum }\end{array}$ & & Fresh & & PCR, sequencing & ITS & [146] \\
\hline $\begin{array}{l}\text { Bupleurum } \\
\text { marginatum var. } \\
\text { stenophyllum }\end{array}$ & & Fresh & & PCR, sequencing & ITS & [146] \\
\hline $\begin{array}{l}\text { Bupleurum } \\
\text { scorzonerifolium }\end{array}$ & & Fresh & & PCR, sequencing & ITS & [146] \\
\hline Bupleurum sibiricum & & Fresh & & $\mathrm{PCR}$, sequencing & ITS & [146] \\
\hline Bupleurum smithii & & Fresh & & $\mathrm{PCR}$, sequencing & ITS & [146] \\
\hline $\begin{array}{l}\text { Bupleurum } \\
\text { tianschanicum }\end{array}$ & & Fresh & & PCR, sequencing & ITS & [146] \\
\hline $\begin{array}{l}\text { Bupleurum } \\
\text { yinchouwense }\end{array}$ & & Fresh & & PCR, sequencing & ITS & [146] \\
\hline \multirow[t]{3}{*}{ Cannabis sativa } & Leaves & Fresh & Yes & ISSR & $\mathrm{N} / \mathrm{A}$ & [88] \\
\hline & $\begin{array}{l}\text { Leaves, stems, } \\
\text { flowering } \\
\text { heads }\end{array}$ & Fresh, dried & & RAPD & N/A & [87] \\
\hline & $\begin{array}{l}\text { Leaves, inflor- } \\
\text { escences }\end{array}$ & Fresh, dried & & AFLP & $\mathrm{N} / \mathrm{A}$ & {$[86]$} \\
\hline Carthamus tinctorius & Leaf & Fresh, crude drug & Yes & $\mathrm{PCR}$, sequencing & $5 S$ gene spacer & [147] \\
\hline $\begin{array}{l}\text { Changium } \\
\text { smyrnioides }\end{array}$ & Leaves & Dried & Yes & RAPD & $\mathrm{N} / \mathrm{A}$ & [148] \\
\hline Codonopsis pilulosa & Roots & Dried & Yes & AP-PCR, RAPD & $\mathrm{N} / \mathrm{A}$ & [109] \\
\hline Corton tiglium & Leaves & Fresh & Yes & $\begin{array}{l}\text { PCR, sequencing; microarray } \\
\text { (silicon) }\end{array}$ & $5 \mathrm{~S}$ gene spacer & [44] \\
\hline Crocus sativus & Leaf & Fresh, crude drug & Yes & PCR, sequencing & $5 S$ gene spacer & [147] \\
\hline
\end{tabular}




\begin{tabular}{|c|c|c|c|c|c|c|}
\hline $\begin{array}{l}\text { Plant } \\
\text { (scientific name) }\end{array}$ & Part & Condition & Voucher & Method & Gene & Ref \\
\hline Cultivated Ephedra & Stem & Fresh & Yes & PCR, sequencing & ITS; trnL; trnL-trnF & [83] \\
\hline Curcuma chuanyujin & & Dried, crude drug & Yes & PCR, sequencing & $5 \mathrm{~S}$ gene spacer & [108] \\
\hline $\begin{array}{l}\text { Curcuma } \\
\text { kwangsiensis }\end{array}$ & & Dried, crude drug & Yes & PCR, sequencing & $5 \mathrm{~S}$ gene spacer & [108] \\
\hline Curcuma longa & & Dried, crude drug & Yes & PCR, sequencing & $5 \mathrm{~S}$ gene spacer & [108] \\
\hline Curcuma phaeocaulis & & Dried, crude drug & Yes & PCR, sequencing & $5 S$ gene spacer & [108] \\
\hline Curcuma wenyujin & & Dried, crude drug & Yes & PCR, sequencing & $5 S$ gene spacer & [108] \\
\hline Datura inoxia & Leaves & Fresh & Yes & $\begin{array}{l}\text { PCR, sequencing; microarray } \\
\text { (silicon) }\end{array}$ & $5 S$ gene spacer & {$[44]$} \\
\hline Datura metel & Leaves & Fresh & Yes & $\begin{array}{l}\text { PCR, sequencing; microarray } \\
\text { (silicon) }\end{array}$ & $5 \mathrm{~S}$ gene spacer & {$[44]$} \\
\hline Datura tatula & Leaves & Fresh & Yes & $\begin{array}{l}\text { PCR, sequencing; microarray } \\
\text { (silicon) }\end{array}$ & $5 S$ gene spacer & {$[44]$} \\
\hline $\begin{array}{l}\text { Dendrobium } \\
\text { acinaforme }\end{array}$ & Leaves, stems & Fresh, dried & & PCR & ITS & [91] \\
\hline \multirow{2}{*}{$\begin{array}{l}\text { Dendrobium } \\
\text { aduncum }\end{array}$} & Stem & Fresh & Yes & PCR, sequencing & ITS & [94] \\
\hline & Leaves, stems & Fresh, dried & & PCR & ITS & [91] \\
\hline \multirow{2}{*}{$\begin{array}{l}\text { Dendrobium } \\
\text { aphyllum }\end{array}$} & Leaves, stems & Fresh, dried & & PCR & ITS & [91] \\
\hline & & & & PCR, sequencing & ITS & [93] \\
\hline $\begin{array}{l}\text { Dendrobium } \\
\text { aurantiacum }\end{array}$ & Leaves, stems & Fresh, dried & & PCR & ITS & [91] \\
\hline $\begin{array}{l}\text { Dendrobium } \\
\text { aurantiacum var. } \\
\text { denneanum }\end{array}$ & Leaves, stems & Fresh, dried & & PCR & ITS & [91] \\
\hline $\begin{array}{l}\text { Dendrobium } \\
\text { auriantiacum }\end{array}$ & Stems & & & Microarray (nylon) & gDNA & [95] \\
\hline $\begin{array}{l}\text { Dendrobium } \\
\text { brymerianum }\end{array}$ & Leaves, stems & Fresh, dried & & PCR & ITS & [91] \\
\hline \multirow{2}{*}{$\begin{array}{l}\text { Dendrobium } \\
\text { candidum (= Den- } \\
\text { drobium officinale) }\end{array}$} & Stem & Fresh & Yes & PCR, sequencing & ITS & [94] \\
\hline & & $\begin{array}{l}\text { Fresh, medicinal } \\
\text { formulation }\end{array}$ & Yes & PCR, microarray (glass) & ITS & [101] \\
\hline $\begin{array}{l}\text { Dendrobium } \\
\text { cantonensis }\end{array}$ & Stem & Fresh & Yes & PCR, sequencing & ITS & [94] \\
\hline $\begin{array}{l}\text { Dendrobium } \\
\text { capillipes }\end{array}$ & Leaves, stems & Fresh, dried & & PCR & ITS & [91] \\
\hline $\begin{array}{l}\text { Dendrobium } \\
\text { cariniferum }\end{array}$ & Leaves, stems & Fresh, dried & & PCR & ITS & [91] \\
\hline \multirow{4}{*}{$\begin{array}{l}\text { Dendrobium } \\
\text { chrysanthum }\end{array}$} & Stem & Fresh & Yes & PCR, sequencing & ITS & [94] \\
\hline & Leaves, stems & Fresh, dried & & PCR & ITS & [91] \\
\hline & & $\begin{array}{l}\text { Fresh, medicinal } \\
\text { formulation }\end{array}$ & Yes & PCR, microarray (glass) & ITS & [101] \\
\hline & & & & PCR, sequencing & ITS & [93] \\
\hline \multirow{4}{*}{$\begin{array}{l}\text { Dendrobium } \\
\text { chrysotoxum }\end{array}$} & Stem & Fresh & Yes & PCR, sequencing & ITS & [94] \\
\hline & Leaves, stems & Fresh, dried & & PCR & ITS & [91] \\
\hline & & $\begin{array}{l}\text { Fresh, medicinal } \\
\text { formulation }\end{array}$ & Yes & PCR, microarray (glass) & ITS & [101] \\
\hline & Stems & & & Microarray (nylon) & gDNA & [95] \\
\hline \multirow{3}{*}{$\begin{array}{l}\text { Dendrobium } \\
\text { crepidatum }\end{array}$} & Stem & Fresh & Yes & PCR, sequencing & ITS & [94] \\
\hline & Leaves, stems & Fresh, dried & & PCR & ITS & [91] \\
\hline & & & & PCR, sequencing & ITS & [93] \\
\hline \multirow{2}{*}{$\begin{array}{l}\text { Dendrobium } \\
\text { crystallinum }\end{array}$} & Leaves, stems & Fresh, dried & & PCR & ITS & [91] \\
\hline & & $\begin{array}{l}\text { Fresh, medicinal } \\
\text { formulation }\end{array}$ & Yes & PCR, microarray (glass) & ITS & [101] \\
\hline \multirow{2}{*}{$\begin{array}{l}\text { Dendrobium } \\
\text { densiflorum }\end{array}$} & Stem & Fresh & Yes & PCR, sequencing & ITS & [94] \\
\hline & Leaves, stems & Fresh, dried & & PCR & ITS & [91] \\
\hline $\begin{array}{l}\text { Dendrobium } \\
\text { densiflorum }\end{array}$ & & $\begin{array}{l}\text { Fresh, medicinal } \\
\text { formulation }\end{array}$ & Yes & PCR, microarray (glass) & ITS & [101] \\
\hline
\end{tabular}




\begin{tabular}{|c|c|c|c|c|c|c|}
\hline \multirow{3}{*}{$\begin{array}{l}\text { Plant } \\
\text { (scientific name) }\end{array}$} & Part & Condition & Voucher & Method & Gene & Ref \\
\hline & Leaves, stems & Fresh, dried & Yes & & ITS & [91] \\
\hline & Leaves, stems & Fresh, dried & & PCR & ITS & [91] \\
\hline $\begin{array}{l}\text { Dendrobium } \\
\text { ellipsophyllum }\end{array}$ & Leaves, stems & Fresh, dried & & PCR & ITS & [91] \\
\hline Dendrobium exile & Leaves, stems & Fresh, dried & & PCR & ITS & [91] \\
\hline \multirow[t]{2}{*}{ Dendrobium falconeri } & Leaves, stems & Fresh, dried & & PCR & ITS & [91] \\
\hline & & $\begin{array}{l}\text { Fresh, medicinal } \\
\text { formulation }\end{array}$ & Yes & PCR, microarray (glass) & ITS & [101] \\
\hline \multirow{4}{*}{$\begin{array}{l}\text { Dendrobium } \\
\text { fimbriatum }\end{array}$} & Stem & Fresh & Yes & $\mathrm{PCR}$, sequencing & ITS & [94] \\
\hline & Leaves, stems & Fresh, dried & & PCR & ITS & [91] \\
\hline & & $\begin{array}{l}\text { Fresh, medicinal } \\
\text { formulation }\end{array}$ & Yes & PCR, microarray (glass) & ITS & [101] \\
\hline & Stems & & & Microarray (nylon) & gDNA & [95] \\
\hline $\begin{array}{l}\text { Dendrobium } \\
\text { fimbriatum var. } \\
\text { occulatum }\end{array}$ & Stem & Fresh & Yes & PCR, sequencing & ITS & [94] \\
\hline $\begin{array}{l}\text { Dendrobium } \\
\text { findlayanum }\end{array}$ & Leaves, stems & Fresh, dried & & PCR & ITS & [91] \\
\hline $\begin{array}{l}\text { Dendrobium } \\
\text { flexicaule }\end{array}$ & Leaves, stems & Fresh, dried & & PCR & ITS & [91] \\
\hline $\begin{array}{l}\text { Dendrobium } \\
\text { funiushanense }\end{array}$ & Leaves, stems & Fresh, dried & & PCR & ITS & [91] \\
\hline \multirow{2}{*}{$\begin{array}{l}\text { Dendrobium } \\
\text { gratiosissimum }\end{array}$} & Leaves, stems & Fresh, dried & Yes & & ITS & [91] \\
\hline & Leaves, stems & Fresh, dried & & PCR & ITS & [91] \\
\hline $\begin{array}{l}\text { Dendrobium } \\
\text { hancockii }\end{array}$ & Leaves, stems & Fresh, dried & & PCR & ITS & [91] \\
\hline $\begin{array}{l}\text { Dendrobium } \\
\text { henanense }\end{array}$ & Leaves, stems & Fresh, dried & & PCR & ITS & [91] \\
\hline \multirow{2}{*}{$\begin{array}{l}\text { Dendrobium } \\
\text { hercoglossum }\end{array}$} & Stem & Fresh & Yes & PCR, sequencing & ITS & [94] \\
\hline & Leaves, stems & Fresh, dried & & PCR & ITS & [91] \\
\hline $\begin{array}{l}\text { Dendrobium } \\
\text { huoshanense }\end{array}$ & Leaves, stems & Fresh, dried & & PCR & ITS & [91] \\
\hline \multirow[t]{2}{*}{ Dendrobium jenkinsii } & Stem & Fresh & Yes & PCR, sequencing & ITS & [94] \\
\hline & & $\begin{array}{l}\text { Fresh, medicinal } \\
\text { formulation }\end{array}$ & Yes & PCR, microarray (glass) & ITS & [101] \\
\hline \multirow[t]{2}{*}{ Dendrobium lindleyi } & Stem & Fresh & Yes & PCR, sequencing & ITS & [94] \\
\hline & & $\begin{array}{l}\text { Fresh, medicinal } \\
\text { formulation }\end{array}$ & Yes & PCR, microarray (glass) & ITS & [101] \\
\hline \multirow{2}{*}{$\begin{array}{l}\text { Dendrobium } \\
\text { lituiflorum }\end{array}$} & Leaves, stems & Fresh, dried & & PCR & ITS & [91] \\
\hline & & & & $\mathrm{PCR}$, sequencing & ITS & [93] \\
\hline \multirow{4}{*}{$\begin{array}{l}\text { Dendrobium } \\
\text { loddigesii }\end{array}$} & Stem & Fresh & Yes & $\mathrm{PCR}$, sequencing & ITS & [94] \\
\hline & Leaves, stems & Fresh, dried & Yes & & ITS & [91] \\
\hline & Leaves, stems & Fresh, dried & & PCR & ITS & [91] \\
\hline & & $\begin{array}{l}\text { Fresh, medicinal } \\
\text { formulation }\end{array}$ & Yes & PCR, microarray (glass) & ITS & [101] \\
\hline \multirow{3}{*}{$\begin{array}{l}\text { Dendrobium } \\
\text { lohohense }\end{array}$} & Stem & Fresh & Yes & PCR, sequencing & ITS & [94] \\
\hline & Leaves, stems & Fresh, dried & & PCR & ITS & [91] \\
\hline & & $\begin{array}{l}\text { Fresh, medicinal } \\
\text { formulation }\end{array}$ & Yes & PCR, microarray (glass) & ITS & [101] \\
\hline $\begin{array}{l}\text { Dendrobium } \\
\text { miniliforme }\end{array}$ & Leaves, stems & Fresh, dried & & PCR & ITS & [91] \\
\hline \multirow{2}{*}{$\begin{array}{l}\text { Dendrobium } \\
\text { moniliforme }\end{array}$} & Stem & Fresh & Yes & $\mathrm{PCR}$, sequencing & ITS & [94] \\
\hline & & $\begin{array}{l}\text { Fresh, medicinal } \\
\text { formulation }\end{array}$ & Yes & PCR, microarray (glass) & ITS & [101] \\
\hline \multirow{2}{*}{$\begin{array}{l}\text { Dendrobium } \\
\text { moschatum }\end{array}$} & Stem & Fresh & Yes & PCR, sequencing & ITS & [94] \\
\hline & & $\begin{array}{l}\text { Fresh, medicinal } \\
\text { formulation }\end{array}$ & Yes & PCR, microarray (glass) & ITS & [101] \\
\hline
\end{tabular}




\begin{tabular}{|c|c|c|c|c|c|c|}
\hline $\begin{array}{l}\text { Plant } \\
\text { (scientific name) }\end{array}$ & Part & Condition & Voucher & Method & Gene & Ref \\
\hline \multirow[t]{4}{*}{ Dendrobium nobile } & Stem & Fresh & Yes & $\mathrm{PCR}$, sequencing & ITS & [94] \\
\hline & Leaves, stems & Fresh, dried & & PCR & ITS & [91] \\
\hline & & $\begin{array}{l}\text { Fresh, medicinal } \\
\text { formulation }\end{array}$ & Yes & PCR, microarray (glass) & ITS & [101] \\
\hline & Stems & & & Microarray (nylon) & gDNA & [95] \\
\hline \multirow{4}{*}{$\begin{array}{l}\text { Dendrobium } \\
\text { officinale }\end{array}$} & Leaves, stems & Fresh, dried & Yes & & ITS & [91] \\
\hline & Leaves, stems & Fresh, dried & & PCR & ITS & [91] \\
\hline & Stems & & & Microarray (nylon) & gDNA & [95] \\
\hline & Stems, leaves & Fresh, Dried & & PCR, sequencing & ITS & {$[90]$} \\
\hline \multirow{2}{*}{$\begin{array}{l}\text { Dendrobium } \\
\text { pendulum }\end{array}$} & Leaves, stems & Fresh, dried & & PCR & ITS & [91] \\
\hline & & $\begin{array}{l}\text { Fresh, medicinal } \\
\text { formulation }\end{array}$ & Yes & PCR, microarray (glass) & ITS & [101] \\
\hline \multirow{3}{*}{$\begin{array}{l}\text { Dendrobium } \\
\text { primulinum }\end{array}$} & Leaves, stems & Fresh, dried & & PCR & ITS & [91] \\
\hline & & $\begin{array}{l}\text { Fresh, medicinal } \\
\text { formulation }\end{array}$ & Yes & PCR, microarray (glass) & ITS & [101] \\
\hline & & & & PCR, sequencing & ITS & [93] \\
\hline $\begin{array}{l}\text { Dendrobium } \\
\text { salaccense }\end{array}$ & Leaves, stems & Fresh, dried & & PCR & ITS & [91] \\
\hline $\begin{array}{l}\text { Dendrobium } \\
\text { thyrsiflorum }\end{array}$ & Leaves, stems & Fresh, dried & & PCR & ITS & [91] \\
\hline $\begin{array}{l}\text { Dendrobium } \\
\text { wardianum }\end{array}$ & Leaves, stems & Fresh, dried & & PCR & ITS & [91] \\
\hline \multirow{2}{*}{$\begin{array}{l}\text { Dendrobium } \\
\text { williamsonii }\end{array}$} & Stem & Fresh & Yes & PCR, sequencing & ITS & [94] \\
\hline & Leaves, stems & Fresh, dried & & PCR & ITS & [91] \\
\hline Digitalis obscura & Leaves & Fresh & & RAPD & & [149] \\
\hline Dioscorea alata & & & & $\mathrm{PCR}$, sequencing & 18S rRNA & [150] \\
\hline Dioscorea japonica & & & & $\mathrm{PCR}$, sequencing & 18S rRNA & [150] \\
\hline Dioscorea persimilis & & & & $\mathrm{PCR}$, sequencing & 18S rRNA & [150] \\
\hline Dioscorea polystachia & & & & $\mathrm{PCR}$, sequencing & 18S rRNA & [150] \\
\hline $\begin{array}{l}\text { Dysosma } \\
\text { aurantiocaulis }\end{array}$ & Leaves & Dried & Yes & PCR, RFLP & $\operatorname{trn} T-\operatorname{trn} L ; \operatorname{trn} D-\operatorname{trn} T$ & [151] \\
\hline Dysosma difformis & Leaves & Dried & Yes & PCR, RFLP & $\operatorname{trnT}$-trnL; trnD-trnT & [151] \\
\hline Dysosma majorensis & Leaves & Dried & Yes & PCR, RFLP & $\operatorname{trn} T$-trnL; $\operatorname{trn} D-\operatorname{trn} T$ & [151] \\
\hline \multirow[t]{2}{*}{ Dysosma pleiantha } & & & & $\begin{array}{l}\text { PCR, sequencing; microarray } \\
\text { (silicon) }\end{array}$ & $5 S$ gene spacer & {$[44]$} \\
\hline & Leaves & Dried & Yes & PCR, RFLP & $\operatorname{trn} T-\operatorname{trn} L ; \operatorname{trn} D-\operatorname{trn} T$ & [151] \\
\hline Dysosma veitchii & Leaves & Dried & Yes & PCR, RFLP & $\operatorname{trn} T-\operatorname{trn} L ; \operatorname{trn} D-\operatorname{trn} T$ & [151] \\
\hline \multirow[t]{2}{*}{ Dysosma versipellis } & & Fresh & & $\begin{array}{l}\text { PCR, sequencing; microarray } \\
\text { (silicon) }\end{array}$ & $5 S$ gene spacer & {$[44]$} \\
\hline & Leaves & Dried & Yes & PCR, RFLP & $\operatorname{trn} T$-trnL; $\operatorname{trn} D-\operatorname{trn} T$ & [151] \\
\hline \multirow[t]{2}{*}{ Echinacea angustifolia } & Leaves & & & RAPD & N/A & [152] \\
\hline & & & & RAPD & $\mathrm{N} / \mathrm{A}$ & [153] \\
\hline $\begin{array}{l}\text { Echinacea } \\
\text { artrorubens }\end{array}$ & & & & RAPD & $\mathrm{N} / \mathrm{A}$ & [152] \\
\hline \multirow[t]{2}{*}{ Echinacea pallida } & & & & RAPD & $\mathrm{N} / \mathrm{A}$ & [152] \\
\hline & & & & RAPD & $\mathrm{N} / \mathrm{A}$ & [153] \\
\hline \multirow[t]{2}{*}{ Echinacea purpurea } & & & & RAPD & $\mathrm{N} / \mathrm{A}$ & [152] \\
\hline & & & & RAPD & $\mathrm{N} / \mathrm{A}$ & [153] \\
\hline Ephedra antisyphilitca & Aerial parts & Dried & Yes & $\mathrm{PCR}$, sequencing & pbsA-trnH & {$[85]$} \\
\hline Ephedra aspera & Aerial parts & Dried & Yes & $\mathrm{PCR}$, sequencing & psbA-trnH & [85] \\
\hline Ephedra californica & Aerial parts & Dried & Yes & $\mathrm{PCR}$, sequencing & psbA-trnH & [85] \\
\hline Ephedra coryi & Aerial parts & Dried & Yes & $\mathrm{PCR}$, sequencing & psbA-trnH & [85] \\
\hline Ephedra distachya & Aerial parts & Dried & Yes & PCR, sequencing & psbA-trnH & [85] \\
\hline \multirow[t]{3}{*}{ Ephedra equisetina } & & Dried, crude drug & Yes & PCR, sequencing; PCR, RFLP & chlB; ITS & [81] \\
\hline & Stem & Fresh & Yes & PCR, sequencing & ITS; trnL; trnL-trnF & [84] \\
\hline & Aerial parts & Dried & Yes & $\mathrm{PCR}$, sequencing & psbA-trnH & [85] \\
\hline Ephedra fasciculata & Aerial parts & Dried & Yes & $\mathrm{PCR}$, sequencing & psbA-trnH & [85] \\
\hline Ephedra fragilis & Aerial parts & Dried & Yes & $\mathrm{PCR}$, sequencing & psbA-trnH & [85] \\
\hline $\begin{array}{l}\text { Ephedra } \\
\text { fedtschenkkoae }\end{array}$ & Aerial parts & Dried & Yes & $\mathrm{PCR}$, sequencing & psbA-trnH & [85] \\
\hline Ephedra foeminea & Aerial parts & Dried & Yes & $\mathrm{PCR}$, sequencing & psbA-trnH & [85] \\
\hline
\end{tabular}




\begin{tabular}{|c|c|c|c|c|c|c|}
\hline $\begin{array}{l}\text { Plant } \\
\text { (scientific name) }\end{array}$ & Part & Condition & Voucher & Method & Gene & Ref \\
\hline Ephedra frustilata & Aerial parts & Dried & Yes & PCR, sequencing & psbA-trnH & [85] \\
\hline Ephedra gerardiana & Stem & Fresh & Yes & PCR, sequencing & ITS; trnL; trnL-trnF & [84] \\
\hline \multirow[t]{2}{*}{ Ephedra intermedia } & & Dried, crude drug & Yes & PCR, sequencing; PCR, RFLP & chlB; ITS & [81] \\
\hline & Stem & Fresh & Yes & $P C R$, sequencing & ITS; trnL; trnL-trnF & [84] \\
\hline \multirow[t]{2}{*}{ Ephedra likiangensis } & Stem & Fresh & Yes & PCR, sequencing & ITS; trnL; trnL-trnF & [84] \\
\hline & Aerial parts & Dried & Yes & PCR, sequencing & psbA-trnH & [85] \\
\hline Ephedra major & Aerial parts & Dried & Yes & PCR, sequencing & psbA-trnH & [85] \\
\hline Ephedra minuta & Stem & Fresh & Yes & PCR, sequencing & ITS; trnL; trnL-trnF & [84] \\
\hline Ephedra monosperma & Stem & Fresh & Yes & PCR, sequencing & ITS; trnL; trnL-trnF & [84] \\
\hline Ephedra nevadensis & Aerial parts & Dried & Yes & PCR, sequencing & psbA-trnH & [85] \\
\hline Ephedra ochreata & Aerial parts & Dried & Yes & $P C R$, sequencing & psbA-trnH & [85] \\
\hline \multirow[t]{3}{*}{ Ephedra przewalskii } & & Dried, crude drug & Yes & PCR, sequencing; RFLP & chlB; ITS & [81] \\
\hline & Stem & Fresh & Yes & $P C R$, sequencing & ITS; trnL; trnL-trnF & [84] \\
\hline & Aerial parts & Dried & Yes & PCR, sequencing & psbA-trnH & [85] \\
\hline Ephedra saxatilis & Aerial parts & Dried & Yes & $P C R$, sequencing & psbA-trnH & [85] \\
\hline \multirow[t]{3}{*}{ Ephedra sinica } & & Dried, crude drug & Yes & PCR, sequencing; PCR, RFLP & chlB; ITS & [81] \\
\hline & Stem & Fresh & Yes & $P C R$, sequencing & ITS; trnL; trnL-trnF & [84] \\
\hline & Aerial parts & Dried & Yes & PCR, sequencing & psbA-trnH & [85] \\
\hline Ephedra trifurca & Aerial parts & Dried & Yes & PCR, sequencing & psbA-trnH & [85] \\
\hline Ephedra torreyana & Aerial parts & Dried & Yes & PCR, sequencing & psbA-trnH & [85] \\
\hline Ephedra viridis & Aerial parts & Dried & Yes & PCR, sequencing & psbA-trnH & [85] \\
\hline $\begin{array}{l}\text { Epimedioum } \\
\text { brevicornu }\end{array}$ & & & Yes & PCR, sequencing & $5 \mathrm{~S}$ gene spacer & [154] \\
\hline Epimedium koreanum & & & Yes & PCR, sequencing & $5 S$ gene spacer & [154] \\
\hline $\begin{array}{l}\text { Epimedium } \\
\text { pubescens }\end{array}$ & & & Yes & $P C R$, sequencing & $5 \mathrm{~S}$ gene spacer & [154] \\
\hline $\begin{array}{l}\text { Epimedium } \\
\text { sagittatum }\end{array}$ & & & Yes & PCR, sequencing & $5 S$ gene spacer & [154] \\
\hline $\begin{array}{l}\text { Epimedium } \\
\text { wushanense }\end{array}$ & & & Yes & PCR, sequencing & $5 S$ gene spacer & [154] \\
\hline Euphorbia discolor & & & Yes & PCR, sequencing & ITS & [155] \\
\hline Euphorbia esula & & & Yes & PCR, sequencing & ITS & [155] \\
\hline Euphorbia kansui & Leaves & Fresh & Yes & $\begin{array}{l}\text { PCR, sequencing; microarray } \\
\text { (silicon) }\end{array}$ & $5 S$ gene spacer & [44] \\
\hline $\begin{array}{l}\text { Euphorbia } \\
\text { lamprocarpa }\end{array}$ & & & Yes & PCR, sequencing & ITS & [155] \\
\hline Euphorbia lathyris & & & Yes & PCR, sequencing & ITS & [155] \\
\hline Euphorbia pekinensis & & & Yes & PCR, sequencing & ITS & [155] \\
\hline Euphorbia peplus & & & Yes & PCR, sequencing & ITS & [155] \\
\hline $\begin{array}{l}\text { Euphorbia } \\
\text { turczaninowii }\end{array}$ & & & Yes & PCR, sequencing & ITS & [155] \\
\hline Fritillaria anhuiensis & Leaves, bulbs & Fresh & Yes & $\begin{array}{l}\mathrm{PCR} \text {, sequencing; restriction } \\
\text { digest }\end{array}$ & $5 \mathrm{~S}$ gene spacer & [77] \\
\hline \multirow[t]{3}{*}{ Fritillaria cirrhosa } & Leaves, bulbs & Fresh & Yes & $\begin{array}{l}\text { PCR, sequencing; restriction } \\
\text { digest }\end{array}$ & $5 S$ gene spacer & [77] \\
\hline & Leaves, bulbs & Dried & Yes & PCR, sequencing; PCR, RFLP & ITS & [80] \\
\hline & & & & $\begin{array}{l}\text { PCR, sequencing; PCR, } \\
\text { microarray (glass) }\end{array}$ & $26 \mathrm{~S}$ rRNA & [79] \\
\hline \multirow[t]{2}{*}{ Fritillaria delavayi } & Leaves, bulbs & Dried & Yes & PCR, sequencing; PCR, RFLP & ITS & [80] \\
\hline & & & & $\begin{array}{l}\text { PCR, sequencing; PCR, } \\
\text { microarray (glass) }\end{array}$ & $26 \mathrm{~S}$ rRNA & [64] \\
\hline Fritillaria hupehensis & Leaves, bulbs & Dried & Yes & PCR, sequencing; PCR, RFLP & ITS & [80] \\
\hline \multirow[t]{2}{*}{ Fritillaria pallidiflora } & Leaves, bulbs & Dried & Yes & PCR, sequencing; PCR, RFLP & ITS & [80] \\
\hline & & & & $\begin{array}{l}\text { PCR, sequencing; PCR, } \\
\text { microarray (glass) }\end{array}$ & $26 \mathrm{~S}$ rRNA & [64] \\
\hline Fritillaria przewalskii & Leaves, bulbs & Dried & Yes & PCR, sequencing; PCR, RFLP & ITS & [80] \\
\hline \multirow[t]{2}{*}{ Fritillaria puqiensis } & Leaves, bulbs & Fresh & Yes & $\begin{array}{l}\mathrm{PCR} \text {, sequencing; restriction } \\
\text { digest }\end{array}$ & $5 \mathrm{~S}$ gene spacer & [77] \\
\hline & Leaves, bulbs & Dried & Yes & PCR, sequencing; PCR, RFLP & ITS & [80] \\
\hline \multirow[t]{2}{*}{ Fritillaria thunbergii } & Leaves, bulbs & Fresh & Yes & $\begin{array}{l}\text { PCR, sequencing; restriction } \\
\text { digest }\end{array}$ & $5 S$ gene spacer & [77] \\
\hline & Leaves, bulbs & Dried & Yes & PCR, sequencing; PCR, RFLP & ITS & [80] \\
\hline $\begin{array}{l}\text { Fritillaria thunbergii } \\
\text { var. chekiangensis }\end{array}$ & & & & $\begin{array}{l}\text { PCR, sequencing; PCR, } \\
\text { microarray (glass) }\end{array}$ & $26 \mathrm{~S}$ rRNA & [64] \\
\hline Fritillaria unibracteata & Leaves, bulbs & Dried & Yes & PCR, sequencing; PCR, RFLP & ITS & {$[80]$} \\
\hline
\end{tabular}




\begin{tabular}{|c|c|c|c|c|c|c|}
\hline \multirow{2}{*}{$\begin{array}{l}\text { Plant } \\
\text { (scientific name) }\end{array}$} & Part & Condition & Voucher & Method & Gene & Ref \\
\hline & & & & $\begin{array}{l}\text { PCR, sequencing; PCR, } \\
\text { microarray (glass) }\end{array}$ & 265 rRNA & {$[64]$} \\
\hline \multirow[t]{2}{*}{ Fritillaria ussurensis } & Leaves, bulbs & Dried & Yes & PCR, sequencing; PCR, RFLP & ITS & {$[80]$} \\
\hline & & & & $\begin{array}{l}\text { PCR, sequencing; PCR, } \\
\text { microarray (glass) }\end{array}$ & 26S rRNA & [64] \\
\hline Fritillaria walujewii & Leaves, bulbs & Dried & Yes & PCR, sequencing; PCR, RFLP & ITS & {$[80]$} \\
\hline Gentiana straminea & & & Yes & $\begin{array}{l}\text { PCR, sequencing; } \\
\text { allele-specific diagnostic PCR }\end{array}$ & rpl16; ITS & [156] \\
\hline \multirow[t]{2}{*}{ Glehnia littoralis } & Leaves & Fresh & & RFLP & $\mathrm{N} / \mathrm{A}$ & [157] \\
\hline & & Fresh, crude drug & Yes & $\mathrm{PCR}$, sequencing & $5 S$ gene spacer & [135] \\
\hline Gnetum gnemon & Aerial parts & Fresh & Yes & $\mathrm{PCR}$, sequencing & psbA-trnH & {$[85]$} \\
\hline $\begin{array}{l}\text { Gnetum } \\
\text { lepostachyum }\end{array}$ & Stems & Fresh & Yes & $\mathrm{PCR}$, sequencing & ITS; trnL; trnL-trnF & {$[84]$} \\
\hline Halenia elliptica & & & Yes & $\begin{array}{l}\text { PCR, sequencing; } \\
\text { allele-specific diagnostic PCR }\end{array}$ & rpl16; ITS & [156] \\
\hline \multirow[t]{2}{*}{ Hedysarum polybotris } & Leaves, roots & Fresh, crude drug & Yes & PCR, sequencing & $5 \mathrm{~S}$ gene spacer & [104] \\
\hline & & & & RAPD & $\mathrm{N} / \mathrm{A}$ & [106] \\
\hline Hemerocallis citrina & Leaf & Fresh, crude drug & Yes & $\mathrm{PCR}$, sequencing & $5 S$ gene spacer & [147] \\
\hline Hermerocallis fulva & Leaf & Fresh, crude drug & Yes & $\mathrm{PCR}$, sequencing & $5 S$ gene spacer & [147] \\
\hline Humulus hops & $\begin{array}{l}\text { Leaves, stems, } \\
\text { flowering } \\
\text { heads }\end{array}$ & Fresh, dried & & RAPD & N/A & [87] \\
\hline Hyoscyamus niger & Leaves & Fresh & Yes & $\begin{array}{l}\text { PCR, sequencing; microarray } \\
\text { (silicon) }\end{array}$ & $5 \mathrm{~S}$ gene spacer & {$[44]$} \\
\hline Lamium amplexicaule & & & & PCR, sequencing & ITS & [158] \\
\hline Leonurus chaituroides & & & & $\mathrm{PCR}$, sequencing & ITS & [158] \\
\hline $\begin{array}{l}\text { Leonurus } \\
\text { heterophyllus }\end{array}$ & & & & $\mathrm{PCR}$, sequencing & ITS & [158] \\
\hline $\begin{array}{l}\text { Leonurus } \\
\text { pseudomacranthus }\end{array}$ & & & & $\mathrm{PCR}$, sequencing & ITS & [158] \\
\hline Leonurus sibiricus & & & & $\mathrm{PCR}$, sequencing & ITS & [158] \\
\hline Ligularia dentata & & & Yes & $\mathrm{PCR}$, sequencing & $5 S$ gene spacer & [159] \\
\hline Ligularia knaitzensis & & & Yes & $\mathrm{PCR}$, sequencing & $5 S$ gene spacer & [159] \\
\hline Ligularia lankongensis & & & Yes & $\mathrm{PCR}$, sequencing & $5 \mathrm{~S}$ gene spacer & [159] \\
\hline Ligularia lapathifolia & & & Yes & $\mathrm{PCR}$, sequencing & $5 S$ gene spacer & [159] \\
\hline Ligularia narynensis & & & Yes & $\mathrm{PCR}$, sequencing & $5 S$ gene spacer & [159] \\
\hline Ligularia nelumbifolia & & & Yes & $\mathrm{PCR}$, sequencing & $5 S$ gene spacer & [159] \\
\hline Ligularia pleurocaulis & & & Yes & $\mathrm{PCR}$, sequencing & $5 S$ gene spacer & [159] \\
\hline Ligularia przewalskii & & & Yes & $\mathrm{PCR}$, sequencing & $5 \mathrm{~S}$ gene spacer & [159] \\
\hline Ligularia sagitta & & & Yes & $\mathrm{PCR}$, sequencing & $5 \mathrm{~S}$ gene spacer & [159] \\
\hline Ligularia subspicata & & & Yes & $\mathrm{PCR}$, sequencing & $5 \mathrm{~S}$ gene spacer & [159] \\
\hline Ligularia tongolensis & & & Yes & $\mathrm{PCR}$, sequencing & $5 S$ gene spacer & [159] \\
\hline Ligularia virgaurea & & & Yes & PCR, sequencing & $5 S$ gene spacer & [159] \\
\hline $\begin{array}{l}\text { Lomatogonium } \\
\text { oreacharis }\end{array}$ & & & Yes & $\begin{array}{l}\text { PCR, sequencing; } \\
\text { allele-specific diagnostic PCR }\end{array}$ & rpl16; ITS & [156] \\
\hline Lycium barbarum & Fruit & Dried & Yes & RAPD & $\mathrm{N} / \mathrm{A}$ & [160] \\
\hline $\begin{array}{l}\text { Lycium barbarum cv. } \\
\text { "Tianjinense" }\end{array}$ & Fruit & Dried & Yes & RAPD & N/A & [160] \\
\hline $\begin{array}{l}\text { Lycium barbarum var. } \\
\text { aranticarpum }\end{array}$ & Fruit & Dried & Yes & RAPD & $\mathrm{N} / \mathrm{A}$ & [160] \\
\hline $\begin{array}{l}\text { Lycium barbarum var. } \\
\text { potaninii }\end{array}$ & Fruit & Dried & Yes & RAPD & $\mathrm{N} / \mathrm{A}$ & [160] \\
\hline Lycium chinense & Fruit & Dried & Yes & RAPD & $\mathrm{N} / \mathrm{A}$ & [160] \\
\hline $\begin{array}{l}\text { Lycium dasy Stemsum } \\
\text { var. rubricaulium }\end{array}$ & Fruit & Dried & Yes & RAPD & $\mathrm{N} / \mathrm{A}$ & [160] \\
\hline Lycium ruthenicum & Fruit & Dried & Yes & RAPD & $\mathrm{N} / \mathrm{A}$ & [160] \\
\hline Lycium truncatum & Fruit & Dried & Yes & RAPD & $\mathrm{N} / \mathrm{A}$ & [160] \\
\hline Medicago sativa & $\begin{array}{l}\text { Leaves; dried } \\
\text { ground } \\
\text { material }\end{array}$ & Fresh, dried & & PCR, sequencing; RFLP & ITS & [161] \\
\hline Mirablis jalapa & Roots & Fresh, dried & Yes & AP-PCR; RAPD & $\mathrm{N} / \mathrm{A}$ & [71] \\
\hline Nandina domestica & & & Yes & $\mathrm{PCR}$, sequencing & $5 S$ gene spacer & [154] \\
\hline Panax assamicus & & & Yes & $\mathrm{PCR}$, sequencing & ITS; trnC-trnD & [69] \\
\hline $\begin{array}{l}\text { Panax bipinnatifidus } \\
\text { var. angustifolius }\end{array}$ & & & Yes & $\mathrm{PCR}$, sequencing & ITS; trnC-trnD & [69] \\
\hline
\end{tabular}




\begin{tabular}{|c|c|c|c|c|c|c|}
\hline $\begin{array}{l}\text { Plant } \\
\text { (scientific name) }\end{array}$ & Part & Condition & Voucher & Method & Gene & Ref \\
\hline $\begin{array}{l}\text { Panax bipinnatifidus } \\
\text { var. bipinnatifidus }\end{array}$ & & & Yes & PCR, sequencing & ITS; trnC-trnD & [69] \\
\hline Panax elegantior & & & Yes & PCR, sequencing & ITS; $\operatorname{trnC}$-trnD & [69] \\
\hline \multirow[t]{8}{*}{ Panax ginseng } & Roots & & & AP-PCR & $\mathrm{N} / \mathrm{A}$ & [17] \\
\hline & Roots & Fresh, dried & Yes & AP-PCR; RAPD & $\mathrm{N} / \mathrm{A}$ & [71] \\
\hline & Roots & Fresh, dried & Yes & RAPD, sequencing; SCAR & $\mathrm{N} / \mathrm{A}$ & [162] \\
\hline & Roots & Fresh, dried & Yes & RAPD, DALP, sequencing & $\mathrm{N} / \mathrm{A}$ & [66] \\
\hline & Leaves, roots & Fresh, crude drug & Yes & MARMS & trnK, $18 \mathrm{~S}$ rRNA & [74] \\
\hline & & & & PCR & SSR & [163] \\
\hline & & Crude drug & & RAPD & N/A & [72] \\
\hline & & & Yes & PCR, sequencing & ITS; trnC-trnD & [69] \\
\hline \multirow[t]{3}{*}{ Panax japonicus } & Leaves, roots & Fresh, crude drug & Yes & MARMS & trnK, $18 \mathrm{~S}$ rRNA & [74] \\
\hline & & Crude drug & & RAPD & N/A & [72] \\
\hline & & & Yes & PCR, sequencing & ITS; $\operatorname{trn} C-\operatorname{trn} D$ & [69] \\
\hline Panax major & & & Yes & $\mathrm{PCR}$, sequencing & ITS; trnC-trnD & [69] \\
\hline \multirow[t]{5}{*}{ Panax notoginseng } & Roots & Fresh, dried & Yes & AP-PCR; RAPD & $\mathrm{N} / \mathrm{A}$ & [71] \\
\hline & Leaves, roots & Fresh, crude drug & Yes & MARMS & trnK, $18 \mathrm{~S}$ rRNA & [74] \\
\hline & & Crude drug & & RAPD & N/A & [72] \\
\hline & & & Yes & PCR, sequencing & ITS; trnC-trnD & [69] \\
\hline & Roots & Fresh & & AFLP; PCR, sequencing & ITS 2 & {$[67]$} \\
\hline Panax omeiensis & & & Yes & PCR, sequencing & ITS; trnC-trnD & [69] \\
\hline Panax pseudoginseng & & & Yes & $\mathrm{PCR}$, sequencing & ITS; trnC-trnD & [69] \\
\hline \multirow[t]{6}{*}{ Panax quinquefolium } & Roots & & & AP-PCR & $\mathrm{N} / \mathrm{A}$ & [17] \\
\hline & Roots & Fresh, dried & Yes & AP-PCR; RAPD & $\mathrm{N} / \mathrm{A}$ & [71] \\
\hline & Roots & Fresh, dried & Yes & RAPD, sequencing; SCAR & $\mathrm{N} / \mathrm{A}$ & [162] \\
\hline & Roots & Fresh, dried & Yes & RAPD, DALP, sequencing & N/A & {$[66]$} \\
\hline & Leaves, roots & Fresh, crude drug & Yes & MARMS & trnK, $18 \mathrm{~S}$ rRNA & [74] \\
\hline & & & & PCR & $\begin{array}{l}\text { Microsatellite } \\
\text { marker }\end{array}$ & [163] \\
\hline \multirow[t]{2}{*}{ Panax quinquefolius } & & Crude drug & & RAPD & $\mathrm{N} / \mathrm{A}$ & [72] \\
\hline & & & Yes & PCR, sequencing & ITS; trnC-trnD & [69] \\
\hline Panax shangianus & & & Yes & $\mathrm{PCR}$, sequencing & ITS; trnC-trnD & [69] \\
\hline Panax sinensis & & & Yes & PCR, sequencing & ITS; trnC-trnD & [69] \\
\hline Panax stipulenatus & & & Yes & PCR, sequencing & ITS; trnC-trnD & [69] \\
\hline Panax trifolius & & & Yes & $\mathrm{PCR}$, sequencing & ITS; trnC-trnD & [69] \\
\hline Panax variabilis & & & Yes & $\mathrm{PCR}$, sequencing & ITS; trnC-trnD & [69] \\
\hline \multirow[t]{2}{*}{ Panax vietnamensis } & Leaves, roots & Fresh, crude drug & Yes & MARMS & trnK, $18 \mathrm{~S}$ rRNA & [74] \\
\hline & & & Yes & PCR, sequencing & ITS; trnC-trnD & [69] \\
\hline Panax wangianus & & & Yes & $\mathrm{PCR}$, sequencing & ITS; trnC-trnD & [69] \\
\hline Panax zingiberensis & & & Yes & PCR, sequencing & ITS; trnC-trnD & [69] \\
\hline Perilla frutescens & & & & PCR, sequencing & ITS & [164] \\
\hline $\begin{array}{l}\text { Perilla frutescens var. } \\
\text { arguta }\end{array}$ & & & & $\mathrm{PCR}$, sequencing & ITS & [164] \\
\hline $\begin{array}{l}\text { Perilla frutescens var. } \\
\text { auriculato-dentata }\end{array}$ & & & & $\mathrm{PCR}$, sequencing & ITS & [164] \\
\hline $\begin{array}{l}\text { Perilla frutescens var. } \\
\text { crispa }\end{array}$ & & & & $\mathrm{PCR}$, sequencing & ITS & [164] \\
\hline Pholidota cantonensis & Stems & Fresh & Yes & PCR, sequencing & ITS & [94] \\
\hline Phyllanthus amarus & & & Yes & $\begin{array}{l}\text { PCR, sequencing; multiplex } \\
\text { PCR }\end{array}$ & ITS; atpB; rbcL & [165] \\
\hline Phyllanthus arenarius & & & Yes & $\begin{array}{l}\text { PCR, sequencing; multiplex } \\
\text { PCR }\end{array}$ & ITS; atpB; rbcL & [165] \\
\hline Phyllanthus calcynus & & & Yes & $\begin{array}{l}\text { PCR, sequencing; multiplex } \\
\text { PCR }\end{array}$ & ITS; atpB; rbcL & [165] \\
\hline Phyllanthus clakei & & & Yes & $\begin{array}{l}\text { PCR, sequencing; multiplex } \\
\text { PCR }\end{array}$ & ITS; atpB; rbcL & [165] \\
\hline $\begin{array}{l}\text { Phyllanthus } \\
\text { cochinchinensis }\end{array}$ & & & Yes & $\begin{array}{l}\text { PCR, sequencing; multiplex } \\
\text { PCR }\end{array}$ & ITS; atpB; rbcL & [165] \\
\hline Phyllanthus distichus & Leaves & Fresh & & RAPD, sequencing SCAR & $\mathrm{N} / \mathrm{A}$ & [166] \\
\hline $\begin{array}{l}\text { Phyllanthus emblica } \\
\text { (= Emblica officinalis) }\end{array}$ & Leaves & Fresh and dried & & RAPD, sequencing; SCAR & $\mathrm{N} / \mathrm{A}$ & [166] \\
\hline $\begin{array}{l}\text { Phyllanthus emblica } \\
\text { (= Emblica officinalis) }\end{array}$ & & & Yes & $\begin{array}{l}\text { PCR, sequencing; multiplex } \\
\text { PCR }\end{array}$ & ITS; atpB; rbcL & [165] \\
\hline Phyllanthus flexuosus & & & Yes & $\begin{array}{l}\text { PCR, sequencing; multiplex } \\
\text { PCR }\end{array}$ & ITS; atpB; rbcL & [165] \\
\hline
\end{tabular}




\begin{tabular}{|c|c|c|c|c|c|c|}
\hline $\begin{array}{l}\text { Plant } \\
\text { (scientific name) }\end{array}$ & Part & Condition & Voucher & Method & Gene & Ref \\
\hline Phyllanthus glaucus & & & Yes & $\begin{array}{l}\text { PCR, sequencing; multiplex } \\
\text { PCR }\end{array}$ & ITS; atpB; rbcL & [165] \\
\hline $\begin{array}{l}\text { Phyllanthus } \\
\text { guangdongensis }\end{array}$ & & & Yes & $\begin{array}{l}\text { PCR, sequencing; multiplex } \\
\text { PCR }\end{array}$ & ITS; atpB; rbcL & [165] \\
\hline $\begin{array}{l}\text { Phyllanthus } \\
\text { hainanensis }\end{array}$ & & & Yes & $\begin{array}{l}\text { PCR, sequencing; multiplex } \\
\text { PCR }\end{array}$ & ITS; atpB; rbcL & [165] \\
\hline $\begin{array}{l}\text { Phyllanthus } \\
\text { indofischeri }\end{array}$ & Leaves & Fresh & & RAPD, sequencing; SCAR & $\mathrm{N} / \mathrm{A}$ & [166] \\
\hline $\begin{array}{l}\text { Phyllanthus } \\
\text { lokohensis }\end{array}$ & & & Yes & $\begin{array}{l}\text { PCR, sequencing; multiplex } \\
\text { PCR }\end{array}$ & ITS; atpB; rbcL & [165] \\
\hline $\begin{array}{l}\text { Phyllanthus } \\
\text { myrtifolius }\end{array}$ & & & Yes & $\begin{array}{l}\text { PCR, sequencing; multiplex } \\
\text { PCR }\end{array}$ & ITS; atpB; rbcL & [165] \\
\hline \multirow{2}{*}{ Phyllanthus niruri } & Leaves & Fresh & & RAPD, sequencing; SCAR, & $\mathrm{N} / \mathrm{A}$ & [166] \\
\hline & & & Yes & $\begin{array}{l}\text { PCR, sequencing; multiplex } \\
\text { PCR }\end{array}$ & ITS; atpB; rbcL & [165] \\
\hline $\begin{array}{l}\text { Phyllanthus } \\
\text { nummulariifolius }\end{array}$ & & & Yes & $\begin{array}{l}\text { PCR, sequencing; multiplex } \\
\text { PCR }\end{array}$ & ITS; atpB; rbcL & [165] \\
\hline $\begin{array}{l}\text { Phyllanthus } \\
\text { parvifolius }\end{array}$ & & & Yes & $\begin{array}{l}\text { PCR, sequencing; multiplex } \\
\text { PCR }\end{array}$ & ITS; atpB; rbcL & [165] \\
\hline $\begin{array}{l}\text { Phyllanthus } \\
\text { reticulatus }\end{array}$ & Leaves & Fresh & & RAPD, sequencing; SCAR & $\mathrm{N} / \mathrm{A}$ & [166] \\
\hline $\begin{array}{l}\text { Phyllanthus } \\
\text { reticulatus }\end{array}$ & & & Yes & $\begin{array}{l}\text { PCR, sequencing; multiplex } \\
\text { PCR }\end{array}$ & ITS; atpB; rbcL & [165] \\
\hline Phyllanthus ruber & & & Yes & $\begin{array}{l}\text { PCR, sequencing; multiplex } \\
\text { PCR }\end{array}$ & ITS; atpB; rbcL & [165] \\
\hline Phyllanthus simplex & Leaves & Fresh & & RAPD, sequencing; SCAR & $\mathrm{N} / \mathrm{A}$ & [166] \\
\hline $\begin{array}{l}\text { Phyllanthus } \\
\text { taxodiifolius }\end{array}$ & & & Yes & $\begin{array}{l}\text { PCR, sequencing; multiplex } \\
\text { PCR }\end{array}$ & ITS; atpB; rbcL & [165] \\
\hline \multirow[t]{2}{*}{ Phyllanthus urinaria } & Leaves & Fresh & & RAPD, sequencing; SCAR & $\mathrm{N} / \mathrm{A}$ & [166] \\
\hline & & & Yes & $\begin{array}{l}\text { PCR, sequencing; multiplex } \\
\text { PCR }\end{array}$ & ITS; atpB; rbcL & [165] \\
\hline $\begin{array}{l}\text { Phyllanthus } \\
\text { ussuriensis }\end{array}$ & & & Yes & $\begin{array}{l}\text { PCR, sequencing; multiplex } \\
\text { PCR }\end{array}$ & ITS; atpB; rbcL & [165] \\
\hline Phyllanthus virgatus & & & Yes & $\begin{array}{l}\text { PCR, sequencing; multiplex } \\
\text { PCR }\end{array}$ & ITS; atpB; rbcL & [165] \\
\hline Phytolacca acinosa & Roots & Fresh, dried & Yes & AP-PCR; RAPD & $\mathrm{N} / \mathrm{A}$ & [71] \\
\hline Pinellia cordata & Leaves & Fresh & Yes & $\begin{array}{l}\text { PCR, sequencing; microarray } \\
\text { (silicon) }\end{array}$ & $5 \mathrm{~S}$ gene spacer & [44] \\
\hline \multirow[t]{2}{*}{ Pinellia pedatisecta } & Leaves & Fresh & Yes & $\begin{array}{l}\text { PCR, sequencing; microarray } \\
\text { (silicon) }\end{array}$ & $5 S$ gene spacer & {$[44]$} \\
\hline & Leaves & Fresh & Yes & PCR, sequencing; PCR-SR & $\begin{array}{l}\text { Mannose-binding } \\
\text { lectin }\end{array}$ & [121] \\
\hline \multirow[t]{2}{*}{ Pinellia pedatisecta } & & & & $\mathrm{PCR}$, sequencing & 18S rRNA & [167] \\
\hline & & & & PCR, sequencing & 18S rRNA & [153] \\
\hline \multirow[t]{5}{*}{ Pinellia ternata } & Leaves & Fresh & Yes & $\begin{array}{l}\text { PCR, sequencing; microarray } \\
\text { (silicon) }\end{array}$ & $5 \mathrm{~S}$ gene spacer & [44] \\
\hline & Leaves & Fresh & Yes & PCR, sequencing; PCR-SR & $\begin{array}{l}\text { Mannose-binding } \\
\text { lectin }\end{array}$ & [121] \\
\hline & & & & RAPD & $\mathrm{N} / \mathrm{A}$ & [168] \\
\hline & & & & $\mathrm{PCR}$, sequencing & 18S rRNA & [167] \\
\hline & & & & $\mathrm{PCR}$, sequencing & 18S rRNA & [153] \\
\hline Plantago ovata & Seedlings & Fresh & & RAPD & N/A & [169] \\
\hline $\begin{array}{l}\text { Platicodon } \\
\text { grandiflorum }\end{array}$ & Roots & Fresh, dried & Yes & AP-PCR; RAPD & $\mathrm{N} / \mathrm{A}$ & [71] \\
\hline Plectranthus barbatus & Leaves & & Yes & AFLP & $\mathrm{N} / \mathrm{A}$ & [170] \\
\hline Plectranthus grandis & Leaves & & Yes & AFLP & $\mathrm{N} / \mathrm{A}$ & [170] \\
\hline Plectranthus ornatus & Leaves & & Yes & AFLP & $\mathrm{N} / \mathrm{A}$ & [170] \\
\hline Pogostemon cablin & & & Yes & $\mathrm{PCR}$, sequencing & 18S rRNA; matK & [136] \\
\hline Pueraria lobata & & & Yes & PCR, sequencing & ITS; 5S gene spacer & [171] \\
\hline Pueraria montana & & & Yes & $\mathrm{PCR}$, sequencing & ITS; 5 S gene spacer & [171] \\
\hline Pueraria thomsonii & & & Yes & $\mathrm{PCR}$, sequencing & ITS; 5 S gene spacer & [171] \\
\hline Pulsatilla vulgaris & Leaves & & Yes & AFLP & $\mathrm{N} / \mathrm{A}$ & [134] \\
\hline Rehmannia chingii & Leaves & Dried & Yes & $\mathrm{PCR}$, sequencing & ITS, trnL-trnF, rps 16 & [18] \\
\hline Rehmannia elata & Leaves & Dried & Yes & $\mathrm{PCR}$, sequencing & ITS, trnL-trnF, rps 16 & [18] \\
\hline Rehmannia glutinosa & Leaves & Dried & Yes & $\mathrm{PCR}$, sequencing & ITS, trnL-trnF, rps 16 & [18] \\
\hline
\end{tabular}




\begin{tabular}{|c|c|c|c|c|c|c|}
\hline $\begin{array}{l}\text { Plant } \\
\text { (scientific name) }\end{array}$ & Part & Condition & Voucher & Method & Gene & Ref \\
\hline Rehmannia henryi & Leaves & Dried & Yes & PCR, sequencing & ITS, trnL-trnF, rps 16 & [18] \\
\hline Rehmannia piasezkii & Leaves & Dried & Yes & PCR, sequencing & ITS, trnL-trnF, rps 16 & [18] \\
\hline Rehmannia solanifolia & Leaves & Dried & Yes & PCR, sequencing & ITS, trnL-trnF, rps16 & [18] \\
\hline Rheum compactum & $\begin{array}{l}\text { Leaves and } \\
\text { roots }\end{array}$ & Dried & Yes & PCR, sequencing & trnL-trnF & [172] \\
\hline Rheum hoatoense & $\begin{array}{l}\text { Leaves and } \\
\text { roots }\end{array}$ & Dried & Yes & PCR, sequencing & $\operatorname{trnL}-\operatorname{trn} F$ & [172] \\
\hline Rheum likiangense & $\begin{array}{l}\text { Leaves and } \\
\text { roots }\end{array}$ & Dried & Yes & PCR, sequencing & $\operatorname{trnL}-\operatorname{trnF}$ & [172] \\
\hline Rheum nanum & $\begin{array}{l}\text { Leaves and } \\
\text { roots }\end{array}$ & Dried & Yes & PCR, sequencing & $\operatorname{trnL}-\operatorname{trn} F$ & [172] \\
\hline Rheum officinale & $\begin{array}{l}\text { Leaves and } \\
\text { roots }\end{array}$ & Dried & Yes & PCR, sequencing & $\operatorname{trnL}-\operatorname{trn} F$ & [172] \\
\hline Rheum palmatum & $\begin{array}{l}\text { Leaves and } \\
\text { roots }\end{array}$ & Dried & Yes & PCR, sequencing & $\operatorname{trnL}-\operatorname{trnF}$ & [172] \\
\hline Rheum przewalskyi & $\begin{array}{l}\text { Leaves and } \\
\text { roots }\end{array}$ & Dried & Yes & PCR, sequencing & $\operatorname{trnL}-\operatorname{trn} F$ & [172] \\
\hline Rheum pumilum & $\begin{array}{l}\text { Leaves and } \\
\text { roots }\end{array}$ & Dried & Yes & PCR, sequencing & $\operatorname{trnL}-\operatorname{trn} F$ & [172] \\
\hline Rheum reticulatum & $\begin{array}{l}\text { Leaves and } \\
\text { roots }\end{array}$ & Dried & Yes & PCR, sequencing & $\operatorname{trnL}-\operatorname{trn} F$ & [172] \\
\hline $\begin{array}{l}\text { Rheum } \\
\text { sublanceolatum }\end{array}$ & $\begin{array}{l}\text { Leaves and } \\
\text { roots }\end{array}$ & Dried & Yes & PCR, sequencing & trnL-trnF & [172] \\
\hline Rheum tanguticum & $\begin{array}{l}\text { Leaves and } \\
\text { roots }\end{array}$ & Dried & Yes & PCR, sequencing & $\operatorname{trnL}-\operatorname{trnF}$ & [172] \\
\hline Rheum undulatum & $\begin{array}{l}\text { Leaves and } \\
\text { roots }\end{array}$ & Dried & Yes & PCR, sequencing & $\operatorname{trnL-trnF}$ & [172] \\
\hline Rheum wittrockii & $\begin{array}{l}\text { Leaves and } \\
\text { roots }\end{array}$ & Dried & Yes & PCR, sequencing & $\operatorname{trnL}-\operatorname{trn} F$ & [172] \\
\hline $\begin{array}{l}\text { Rhodiola } \\
\text { chrysanthemifolia }\end{array}$ & Leaves & Fresh & & ISSR-PCR & $\mathrm{N} / \mathrm{A}$ & [173] \\
\hline Rhododendrom molle & & & & $\begin{array}{l}\text { PCR, sequencing; microarray } \\
\text { (silicon) }\end{array}$ & $5 \mathrm{~S}$ gene spacer & {$[44]$} \\
\hline Salvia bowleyana & & & & PCR, sequencing & ITS & [174] \\
\hline Salvia chinensis & & & & PCR, sequencing & ITS & [174] \\
\hline Salvia miltiorrhiza & & & & PCR, sequencing & ITS & [174] \\
\hline $\begin{array}{l}\text { Salvia miltiorrhiza } f \text {. } \\
\text { alba }\end{array}$ & & & & PCR, sequencing & ITS & [174] \\
\hline Salvia plebeia & & & & PCR, sequencing & ITS & [174] \\
\hline Salvia przewalskii & & & & PCR, sequencing & ITS & [174] \\
\hline Salvia substonifara & & & & PCR, sequencing & ITS & [174] \\
\hline Salvia trijuga & & & & PCR, sequencing & ITS & [174] \\
\hline Salvia yunnanensis & & & & PCR, sequencing & ITS & [174] \\
\hline Scutellaria altissima & Leaves & Fresh & Yes & PCR, sequencing & rpl16; rpl16-rpl14 & [175] \\
\hline \multirow[t]{3}{*}{ Scutellaria baicalensis } & Leaves & Fresh & Yes & PCR, sequencing & rpl16; rpl16-rpl14 & [175] \\
\hline & & & & RAPD & $\mathrm{N} / \mathrm{A}$ & [176] \\
\hline & Leaves & & Yes & RAPD & $\mathrm{N} / \mathrm{A}$ & [177] \\
\hline \multirow{2}{*}{$\begin{array}{l}\text { Scutellaria } \\
\text { gelericulata }\end{array}$} & Leaves & Fresh & Yes & PCR, sequencing & rpl16; rpl16-rpl14 & [175] \\
\hline & Leaves & & Yes & RAPD & $N / A$ & [177] \\
\hline Scutellaria incana & Leaves & Fresh & Yes & PCR, sequencing & rpl16; rpl16-rpl14 & [175] \\
\hline Scutellaria indica & Leaves & Fresh & Yes & PCR, sequencing & rpl16; rpl16-rpl14 & [175] \\
\hline \multirow[t]{2}{*}{ Scutellaria laterifloria } & Leaves & Fresh & Yes & PCR, sequencing & rpl16; rpl16-rpl14 & [175] \\
\hline & Leaves & & Yes & RAPD & N/A & [177] \\
\hline $\begin{array}{l}\text { Sinopodophyllum } \\
\text { hexandrum }\end{array}$ & Leaves & Dried & Yes & PCR, RFLP & $\operatorname{trnT}$-trnL; trnD-trnT & [151] \\
\hline Stellera chamaejasme & & & & $\begin{array}{l}\text { PCR, sequencing; microarray } \\
\text { (silicon) }\end{array}$ & $\operatorname{trn} L$ & [44] \\
\hline Strychnos nux-vomica & Leaves & Fresh & Yes & $\begin{array}{l}\text { PCR, sequencing; microarray } \\
\text { (silicon) }\end{array}$ & $5 S$ gene spacer & [44] \\
\hline Swertia angustifolia & & & Yes & $\begin{array}{l}\text { PCR, sequencing; } \\
\text { allele-specific diagnostic PCR }\end{array}$ & rpl16; ITS & [156] \\
\hline Swertia chirayita & & & Yes & $\begin{array}{l}\text { PCR, sequencing; } \\
\text { allele-specific diagnostic PCR }\end{array}$ & rpl16; ITS & [156] \\
\hline
\end{tabular}




\begin{tabular}{|c|c|c|c|c|c|c|}
\hline $\begin{array}{l}\text { Plant } \\
\text { (scientific name) }\end{array}$ & Part & Condition & Voucher & Method & Gene & Ref \\
\hline Swertia dichotoma & & & Yes & $\begin{array}{l}\text { PCR, sequencing; } \\
\text { allele-specific diagnostic PCR }\end{array}$ & rpl16; ITS & [156] \\
\hline Swertia erythrosticta & & & Yes & $\begin{array}{l}\text { PCR, sequencing; } \\
\text { allele-specific diagnostic PCR }\end{array}$ & rpl16; ITS & [156] \\
\hline Swertia luquanensis & & & Yes & $\begin{array}{l}\text { PCR, sequencing; } \\
\text { allele-specific diagnostic PCR }\end{array}$ & rpl16; ITS & [156] \\
\hline Swertia macrosperma & & & Yes & $\begin{array}{l}\text { PCR, sequencing; } \\
\text { allele-specific diagnostic PCR }\end{array}$ & rpl16; ITS & [156] \\
\hline Swertia mileensis & & & Yes & $\begin{array}{l}\text { PCR, sequencing; } \\
\text { allele-specific diagnostic PCR }\end{array}$ & rpl16; ITS & [156] \\
\hline Swertia mussotii & & & Yes & $\begin{array}{l}\mathrm{PCR} \text {, sequencing; } \\
\text { allele-specific diagnostic PCR }\end{array}$ & rpl16; ITS & [156] \\
\hline Swertia prsewalskii & & & Yes & $\begin{array}{l}\text { PCR, sequencing; } \\
\text { allele-specific diagnostic PCR }\end{array}$ & rpl16; ITS & [156] \\
\hline Swertia punicea & & & Yes & $\begin{array}{l}\text { PCR, sequencing; } \\
\text { allele-specific diagnostic PCR }\end{array}$ & rpl16; ITS & [156] \\
\hline Swertia tetraptera & & & Yes & $\begin{array}{l}\text { PCR, sequencing; } \\
\text { allele-specific diagnostic PCR }\end{array}$ & rpl16; ITS & [156] \\
\hline Talinum paniculatum & Roots & Fresh, dried & Yes & AP-PCR; RAPD & $\mathrm{N} / \mathrm{A}$ & [71] \\
\hline Trifolium pratense & $\begin{array}{l}\text { Leaves; dried } \\
\text { ground } \\
\text { material }\end{array}$ & Fresh, dried & & PCR, sequencing; RFLP & ITS & [161] \\
\hline Thymus vulgaris & Leaves & & & RAPD & $N / A$ & [178] \\
\hline $\begin{array}{l}\text { Typhonium } \\
\text { divaricatum }\end{array}$ & Leaves & Fresh & Yes & $\begin{array}{l}\text { PCR, sequencing; } \\
\text { microarray (silicon) }\end{array}$ & $5 S$ gene spacer & [44] \\
\hline $\begin{array}{l}\text { Typhonium } \\
\text { flagelliforme }\end{array}$ & Leaves & Fresh & & RAPD & $\mathrm{N} / \mathrm{A}$ & [179] \\
\hline $\begin{array}{l}\text { Typhonium } \\
\text { giganteum }\end{array}$ & Leaves & Fresh & Yes & $\begin{array}{l}\text { PCR, sequencing; } \\
\text { microarray (silicon) }\end{array}$ & $5 S$ gene spacer & [44] \\
\hline Typhonium roxburghii & Leaves & Fresh & & RAPD & $\mathrm{N} / \mathrm{A}$ & [179] \\
\hline $\begin{array}{l}\text { Typhonium } \\
\text { trilobatum }\end{array}$ & Leaves & Fresh & & RAPD & $\mathrm{N} / \mathrm{A}$ & [179] \\
\hline Vitex rotundifolia & $\begin{array}{l}\text { Fruits and } \\
\text { leaves }\end{array}$ & Fresh & Yes & ISSR-PCR & $N / A$ & [19] \\
\hline Welwitschia mirabilis & Aerial parts & Fresh & Yes & PCR, sequencing & psbA-trnH & [85] \\
\hline
\end{tabular}

as input [20]. Although the overall results were similar, these authors found that the 5S rRNA spacer exhibited more sequence variation than either the ITS or $18 \mathrm{~S}$ coding sequences and therefore proved best suited for the phylogenetic analysis of the Astagalus taxa examined [20]. Although the levels of isoflavonoids and astragalosides in each of 10 Astragalus taxa collected from 28 different regions exhibited variation, the phytochemical profiles did not allow for species level differentiation [110].

\section{Conclusions}

A large number of molecular techniques have been used to authenticate medicinal plants based on species-specific variations in the sequences of various chloroplast and nuclear DNA regions. Using PCR-based methods, species identification has been achieved using DNA that was isolated from fresh and dried plant parts, plant extracts, processed herbal drugs, as well as finished products such as herbal teas, tablets and capsules. Genomic fingerprinting can differentiate between individuals, species and populations and has proven useful for the characterization of sample homogeneity and detection of adulterants.

DNA-based authentication of medicinal plants is a work in progress that offers powerful new tools and entry points for measures aimed at quality control and quality assurance in medical plant research as well as the production, clinical use, and foren- sic examination of herbal medicines. For example, genomebased methods can be useful in quickly and efficiently pinpointing adulterated or misidentified raw materials, which can then be discarded without further need for time- and resource-consuming morphological, physical and phytochemical examinations. However, DNA-based species identification alone will rarely be sufficient for quality control and assurance because, as living organisms, plants are the product of both the genome and the environment. Although both qualitative and quantitative properties of plant metabolic pathways are largely predetermined genetically, overall metabolic activity is strongly influenced by the environment. Moreover, metabolites are often distributed unequally in different parts of the plant such as roots, stems or leaves, for example. Considering the important role that the chemical metabolites are thought to play in mediating the pharmacologic effects of herbal medicines [111], [112], the importance of extensive and standardized phytochemical characterization of medicinal plants by chromatographic and spectroscopic methods will continue to grow [113].

\section{References}

1 Hart BL. The evolution of herbal medicine: behavioral perspectives. Anim Behav 2005; 70: 975 - 89

2 Halberstein RA. Medicinal plants: historical and cross-cultural usage patterns. AEP 2005; 15: 686-99 
3 Huffman MA. Self-medicative behavior in the African great apes: an evolutionary perspective into the origins of human traditional medicine. Bioscience 2001; 51: $651-61$

4 Krief S, Hladik CM, Haxaire C. Ethnomedicinal and bioactive properties of plants ingested by wild chimpanzees in Uganda. J Ethnopharmacol 2005; 101: 1 - 15

5 Jones WP, Chin $Y-W$, Kinghorn $A D$. The role of pharmacognosy in modern medicine and pharmacy. Current Drug Targets 2006; 7: 247 - 64

6 Koehn FE, Carter GT. The evolving role of natural products in drug discovery. Nat Rev Drug Discov 2005; 4: 206 - 20

7 Newman DJ, Cragg GM, Snader KM. The influence of natural products upon drug discovery. Nat Prod Rep 2000; 17: 215 - 34

8 Newman DJ, Cragg GM, Snader KM. Natural products as sources of new drugs over the period 1981 - 2002. J Nat Prod 2003; 66: 1022 - 37

9 WHO traditional medicine strategy 2002-2005. Geneva: World Health Organization Geneva; 2002

10 Ernst E. The efficacy of herbal medicine - an overview. Fundam Clin Pharmacol 2005; 19: 405-9

11 Tindle HA, Davis RB, Phillips RS, Eisenberg DM. Trends in use of complementary and alternative medicine by US adults: 1997-2002. Altern Ther Health Med 2005; 11: 42 - 9

12 Cardellina JHI. Challenges and opportunities confronting the botanical dietary supplement industry. J Nat Prod 2002; 65: 1073-84

13 Ernst E. Herbal medicines - they are popular, but are they also safe? Eur J Clin Pharmacol 2006; 62: 1 - 2

14 Zhonghua Renmin Gongheguo wei sheng bu yao dian wei yuan hui. Pharmacopoeia of the People's Republic of China. English ed. Beijing: Chemical Industry Press; 2000

15 Chinese Drug Monographs and Analysis. Kötzing: Verlag für Ganzheitliche Medizin Dr. Erich Wühr GmbH; 2004

16 Zhao Z, Hu Y, Liang Z, Yuen JP, Jiang Z, Leung KS. Authentication is fundamental for standardization of Chinese medicines. Planta Med 2006; 72: $865-74$

17 Cheung KS, Kwan HS, But PP, Shaw PC. Pharmacognostical identification of American and Oriental ginseng roots by genomic fingerprinting using arbitrarily primed polymerase chain reaction (AP-PCR). J Ethnopharmacol 1994; 42: 67 - 9

18 Albach DC, Li HQ Zhao N, Jensen SR. Molecular systematics and phyotchemistry of Rehmannia (Scrophulariaceae). Biochem Syst Ecol 2007; 35: $293-300$

$19 \mathrm{Hu}$ Y, Zhang $\mathrm{Q}$ Xin H, Qin LP, Lu BR, Rahman K et al. Association between chemical and genetic variation of Vitex rotundifolia populations from different locations in China: its implication for quality control of medicinal plants. Biomed Chromatogr 2007; 21: $967-75$

20 Dong TT, Ma XQ Clarke C, Song ZH, Ji ZN, Lo CK et al. Phylogeny of Astragalus in China: molecular evidence from the DNA sequences of 5S rRNA spacer, ITS, and 18S rRNA. J Agric Food Chem 2003; 51 : $6709-14$

21 Yamaji H, Fukuda T, Yokoyama J, PakJ-H, Zhou C, Yang C et al. Reticulate evolution and phylogeography in Asarum sect. asiasarum (Aristolochiaceae) documented in internal transcribed spacer sequences (ITS) of nuclear ribosomal DNA. Mol Phylogenet Evol 2007; 44: 863 84

22 Soltis PS, Gitzendanner MA. Molecular systematics and the conservation of rare species. Conserv Biol 1999; 13: 471 - 83

23 Mizukami H, Ohbayashi K, Kitamura Y, Ikenaga T. Restriction fragment length polymorphisms (RFLPs) of medicinal plants and crude drugs. I. RFLP probes allow clear identification of Duboisia interspecific hybrid genotypes in both fresh and dried tissues. Biol Pharm Bull 1993; 16: $388-90$

24 Crawford DJ. Plant macromolecular systematics in the past 50 years: one view. Taxon 2000; 49: 479-501

25 Hillis DM. Molecular versus morphological approaches to systematics. Annu Rev Ecol Syst 1987; 18: $23-42$

26 Bartlett J, Stirling D. A short history of the polymerase chain reaction. In: Bartlett J, Stirling D, editors. Methods in molecular biology: PCR protocols, 2nd edition Totowa, NJ: Humana Press Inc.; 2003: 1 - 6

27 Hebert PDN, Cywinska A, Ball SL, deWaard JR. Biological identification through DNA barcodes. Proc R Soc Lond B Biol Sci 2003; 270: 313 - 21

28 Savolainen V, Cowan RS, Vogler AP, Roderick GK, Lane R. Towards writing the encyclopedia of life: an introductin to DNA barcoding. Philos Trans R Soc Lond B Biol Sci 2005; 360: 1805-11

29 Ratnasingham S, Hebert PDN. BOLD: the barcode of life data system (www.barcodinglife.org). Mol Ecol Notes 2007; 7: 355 - 64
30 Porkert $M$. The theoretical foundations of Chinese medicine: systems of correspondence. Cambridge: MIT Press; 1973: 368

31 Hu Z, Yang X, Ho PC, Chan SY, Heng PW, Chan E et al. Herb-drug interactions: a literature review. Drugs 2005; 65: 1239-82

32 Miller LG. Herbal medicinals: selected clinical considerations focusing on known or potential drug-herb interactions. Arch Intern Med 1998; 158: $2200-11$

33 Chen CF, Shum YC, Yang SP. The modernization of traditional Chinese medicine in Taiwan-past, present and future. Adv Exp Med Biol 2004; 546: $35-42$

34 Zhu YP, Woerdenbag HJ. Traditional Chinese herbal medicine. Pharm World Sci 1995; 17: $103-12$

35 Yu F, Takashi T, Morya J, Kawaura K, Yamakawa J, Kusaka K et al. Tradtitional Chinese medicine and Kampo: a review from the distant past for the future. JInt Med 2006; 34: 231 -9

36 Saito $H$. Regulation of herbal medicines in Japan. Pharmacol Res 2000; 41: $515-9$

37 Williams JG, Kubelik AR, Livak KJ, Rafalski JA, Tingey SV. DNA polymorphisms amplified by arbitrary primers are useful as genetic markers. Nucleic Acids Res 1990; 18: 6531 -5

38 Botstein D, White RL, Skolnick M, Davis RW. Construction of a genetic linkage map in man using restriction fragment length polymorphisms. Am J Hum Genet 1980; 32: 314- 31

39 Shaw PC, Wang J, But PP-H. Authentication of Chinese medicinal materials by DNA technology. Singapore: World Scientific Publishing Co. Pte. Ltd.; 2002

40 Dittrich PS, Tachikawa K, Manz A. Micro total analysis systems. Latest advancements and trends. Anal Chem 2006; 78: 3887 -908

41 Reyes DR, Iossifidis D, Auroux PA, Manz A. Micro total analysis systems. 1. Introduction, theory, and technology. Anal Chem 2002; 74: 2623 36

42 Auroux PA, Iossifidis D, Reyes DR, Manz A. Micro total analysis systems. 2. Analytical standard operations and applications. Anal Chem 2002; 74: $2637-52$

43 Auroux PA, Koc Y, deMello A, Manz A, Day PJ. Miniaturised nucleic acid analysis. Lab Chip 2004; 4: 534-46

44 Carles M, Cheung MK, Moganti S, Dong TT, Tsim KW, Ip NY et al. A DNA microarray for the authentication of toxic traditional Chinese medicinal plants. Planta Med 2005; 71: $580-4$

45 Carles M, Lee T, Moganti S, Lenigk R, Tsim KW, Ip NY et al. Chips and Qi: microcomponent-based analysis in traditional Chinese medicine. Fresenius J Anal Chem 2001; 371: $190-4$

46 Trau D, Lee TM, Lao AI, Lenigk R, Hsing IM, Ip NY et al. Genotyping on a complementary metal oxide semiconductor silicon polymerase chain reaction chip with integrated DNA microarray. Anal Chem 2002; 74: $3168-73$

47 Lee TM, Carles MC, Hsing IM. Microfabricated PCR-electrochemical device for simultaneous DNA amplification and detection. Lab Chip 2003; $3: 100-5$

48 Lee TM, Hsing IM, Lao AI, Carles MC. A miniaturized DNA amplifier: its application in traditional Chinese medicine. Anal Chem 2000; 72: $4242-7$

49 Trau D, Jiang J, Sucher NJ. Preservation of the biofunctionality of DNA and protein during microfabrication. Langmuir 2006; 22: 877-81

50 Bennett MD, Leitch IJ. Nuclear DNA amounts in angiosperms: progress, problems and prospects. Ann Bot 2005; 95: 45 - 90

51 Lilly JW, Havey MJ, Jackson SA, Jiang J. Cytogenomic analyses reveal the structural plasticity of the chloroplast genome in higher plants. Plant Cell 2001; 13: $245-54$

52 Levings CS, Brown GG. Molecular biology of plant mitochondria. Cell 1989; 56: $171-9$

53 Kress WJ, Wurdack KJ, Zimmer EA, Weigt LA, Janzen DH. Use of DNA barcodes to identify flowering plants. Proc Natl Acad Sci U S A 2005; 102: $8369-74$

54 Newmaster SG, Fazekas AJ, Ragupathy S. DNA barcoding in land plants: evaluation of rbcL in a multigene tiered approach. Can J Bot/Rev Can Bot 2006; 84: $335-41$

55 Olmstead RG, Palmer JD. Chloroplast DNA systematics: a review of methods and data analysis. Am J Bot 1994; 81: 1205 - 24

56 Palmer JD, Jansen RK, Micheals HJ, Chase MW, Manhart JR. Chloroplast DNA variation and plant phylogeny. Ann Mo Bot Gard 1988; 75: 1180 206

57 Small RL, Cronn RC, Wendel JF. Use of nuclear genes for phylogeny reconstruction in plants. Aust Syst Bot 2004; 17: 145 - 70 
58 Baldwin BG, Sanderson MJ, Wojciechowski MF, Campbell CS, Donoghue $M J$. The ITS region of nuclear ribosomal DNA: a valuable source of evidence on angiosperm phylogeny. Ann Mo Bot Gard 1995; 82: 247 - 77

59 Álvarez I, Wendel JF. Ribosomal ITS sequences and plant phylogenetic inference. Mol Phylogenet Evol 2003; 29: 417 - 34

60 Hillis DM, Dixon MT. Ribosomal DNA: molecular evolution and phylogenetic inference. Q Rev Biol 1991; 66: 411 - 53

61 Hori $\mathrm{H}$, Osawa $\mathrm{S}$. Origin and evolution of organisms as deduced from 5S ribosomal RNA sequences. Mol Biol Evol 1987; 4: 445 - 72

62 Pennisi E. TAXONOMY: Wanted: A Barcode for Plants. Science 2007; 318: $190-1$

63 Cui GH, Tang XJ, Huang LQ. [Application of multiplex allele-specific PCR for authentication of Panax ginseng and P. quinquefolius]. Zhongguo Zhong Yao Za Zhi 2006; 31: 1940-3

64 Cui XM, Lo CK, Yip KL, Dong TT, Tsim KW. Authentication of Panax notoginseng by 5S-rRNA spacer domain and random amplified polymorphic DNA (RAPD) analysis. Planta Med 2003; 69: 584-6

65 Ha WY, Shaw PC, Liu J, Yau FC, Wang J. Authentication of Panax ginseng and Panax quinquefolius using amplified fragment length polymorphism (AFLP) and directed amplification of minisatellite region DNA (DAMD). J Agric Food Chem 2002; 50: 1871 - 5

66 Ha WY, Yau FC, But PP, Wang J, Shaw PC. Direct amplification of length polymorphism analysis differentiates Panax ginseng from $P$. quinquefolius. Planta Med 2001; 67: 587-9

67 Hong DY, Lau AJ, Yeo CL, Liu XK, Yang CR, Koh HL et al. Genetic diversity and variation of saponin contents in Panax notoginseng roots from a single farm. J Agric Food Chem 2005; 53: 8460 - 7

68 Komatsu K, Zhu S, Fushimi H, Qui TK, Cai S, Kadota S. Phylogenetic analysis based on 18S rRNA gene and matK gene sequences of Panax vietnamensis and five related species. Planta Med 2001; 67: 461-5

69 Lee C, Wen J. Phylogeny of Panax using chloroplast trnC-trnD intergenic region and the utility of trnC-trnD in interspecific studies of plants. Mol Phylogenet Evol 2004; 31: 894 - 903

70 Mihalov JJ, Marderosian AD, Pierce JC. DNA identification of commercial ginseng samples. J Agric Food Chem 2000; 48: 3744-52

71 Shaw PC, But PP. Authentication of Panax species and their adulterants by random-primed polymerase chain reaction. Planta Med 1995; 61: 466-9

72 Tanaka H, Fukuda N, Shoyama Y. Identification and differentiation of Panax species using ELISA, RAPD and eastern blotting. Phytochem Anal 2006; 17: 46-55

73 Um JY, Chung HS, Kim MS, Na HJ, Kwon HJ, Kim IJ et al. Molecular authentication of Panax ginseng species by RAPD analysis and PCRRFLP. Biol Pharm Bull 2001; 24: 872 - 5

74 Zhu S, Fushimi H, Cai S, Komatsu K. Phylogenetic relationship in the genus Panax: inferred from chloroplast trnK gene and nuclear 18S rRNA gene sequences. Planta Med 2003; 69: 647-53

75 Zhu S, Fushimi H, Cai S, Komatsu K. Species identification from Ginseng drugs by multiplex amplification refractory mutation system (MARMS). Planta Med 2004; 70: 189-92

76 Bian Y, Li P, Gao Z, Wang Y, Zhou K, Tsim KW et al. [Application of RAPD in the taxonomy of the genus Fritillaria]. Zhong Yao Cai 2000; $23: 13-$

77 Cai ZH, Li P, Dong TT, Tsim KW. Molecular diversity of 5S-rRNA spacer domain in Fritillaria species revealed by PCR analysis. Planta Med 1999; 65: $360-4$

78 Li YF, Li YX, Lin J, Xu Y, Yan F, Tang L et al. Identification of bulb from Fritillaria cirrhosa by PCR with specific primers. Planta Med 2003; 69: $186-8$

79 Tsoi PY, Woo HS, Wong MS, Chen SL, Fong WF, Xiao PG et al. Genotyping and species identification of Fritillaria by DNA chips. Yao Xue Xue Bao 2003; 38: 185 - 90

80 Wang CZ, Li P, Ding JY, Jin GQ Yuan CS. Identification of Fritillaria pallidiflora using diagnostic PCR and PCR-RFLP based on nuclear ribosomal DNA internal transcribed spacer sequences. Planta Med 2005; 71: $384-6$

81 Guo Y, Tsuruga A, Yamaguchi S, Oba K, Iwai K, Sekita S et al. Sequence analysis of chloroplast chlB gene of medicinal Ephedra species and its application to authentication of Ephedra herb. Biol Pharm Bull 2006; 29: $1207-11$

82 Joshi VC, Khan I. Macroscopic and microscopic authentication of Chinese and North American species of Ephedra. J AOAC Int 2005; 88: $707-13$
83 Kakiuchi N, Nakajima I, Kurita Y, Long C, Cai S, Mikage M. Studies on cultivated Ephedra plants in inner Mongolia autonomous region and Ningxia autonomous region. Biol Pharm Bull 2006; 29: 746 - 9

84 Long C, Kakiuchi N, Takahashi A, Komatsu K, Cai S, Mikage M. Phylogenetic analysis of the DNA sequence of the non-coding region of nuclear ribosomal DNA and chloroplast of Ephedra plants in China. Planta Med 2004; 70: 1080-4

85 Techen N, Khan IA, Pan Z, Scheffler BE. The use of polymerase chain reaction (PCR) for the identification of ephedra DNA in dietary supplements. Planta Med 2006; 72: $241-7$

86 Datwyler SL, Weiblen GD. Genetic variation in hem and maijuana (Cannabis sativa L.) according to amplified fragment length polymorphisms. J Forensic Sci 2006; 51: 371 -5

87 Jagadish V, Robertson J, Gibbs A. RAPD analysis distingishes Cannabis sativa samples from different sources. Forensic Sci Int 1996; 79: $113-21$

88 Kojoma M, Iida O, Makino Y, Sekita S, Satake M. DNA fingerprinting of Cannabis sativa using inter-simple sequence repeat (ISSR) amplification. Planta Med 2002; 68: 60 -3

89 Ding G, Ding XY, Shen J, Tang F, Liu DY, He J et al. [Genetic diversity and molecular authentication of wild populations of Dendrobium officinale by RAPD]. Yao Xue Xue Bao 2005; 40: 1028 - 32

90 Ding X, Wang Z, Zhou K, Xu L, Xu H, Wang Y. Allele-specific primers for diagnostic PCR authentication of Dendrobium officinale. Planta Med 2003; 69: $587-8$

91 Ding X, Xu L, Wang Z, Zhou K, Xu H, Wang Y. Authentication of stems of Dendrobium officinale by rDNA ITS region sequences. Planta Med 2002; 68: $191-2$

92 Ding XY, Wang ZT, Xu H, Xu LS, Zhou KY. [Database establishment of the whole rDNA ITS region of Dendrobium species of "fengdou" and authentication by analysis of their sequences]. Yao Xue Xue Bao 2002; 37: $567-73$

93 Ding XY, Xu LS, Wang ZT, Xu H, Zhou KY. [Molecular authentication of Dendrobium chrysanthum from its allied species of Dendrobium] Zhongguo Zhong Yao Za Zhi 2002; 27: 407-11

94 Lau DT, Shaw PC, Wang J, But PP. Authentication of medicinal Dendrobium species by the internal transcribed spacer of ribosomal DNA. Planta Med 2001; 67: 456-60

95 Li T, Wang J, Lu Z. Accurate identification of closely related Dendrobium species with multiple species-specific gDNA probes. J Biochem Biophys Methods 2005; 62: $111-23$

96 Shen J, Ding XY, Ding G, Liu DY, Tang F, He J. [Studies on population difference of Dendrobium officinale II establishment and optimization of the method of ISSR fingerprinting marker]. Zhongguo Zhong Yao Za Zhi 2006; 31: 291 - 4

$97 X u H$, Li XB, Wang ZT, Ding XY, Xu LS, Zhou KY. [rDNA its sequencing of Herba Dendrobii (Huangcao)]. Yao Xue Xue Bao 2001; 36: 777- 83

98 Ying $Y, X u H$, Wang $Z$ T. [Allele-specific diagnostic PCR authentication of Dendrobium thyrsiflorum]. Yao Xue Xue Bao 2007; 42: 98 - 103

99 Zhang M, Huang HR, Liao SM, Gao JY. [Cluster analysis of Dendrobium by RAPD and design of specific primer for Dendrobium candidum] Zhongguo Zhong Yao Za Zhi 2001; 26: $442-7$

100 Zhang T, Xu LS, Wang ZT, Zhou KY, Zhang N, Shi YF. [Molecular identification of medicinal plants: Dendrobium chrysanthum, Dendrobium fimbriatum and their morphologically allied species by PCR-RFLP analyses]. Yao Xue Xue Bao 2005; 40: 728-33

101 Zhang YB, Wang J, Wang ZT, But PP, Shaw PC. DNA microarray for identification of the herb of Dendrobium species from Chinese medicinal formulations. Planta Med 2003; 69: 1172 - 4

102 Chen G, Wang XL, Wong WS, Liu XD, Xia B, Li N. Application of 3' untranslated region (UTR) sequence-based amplified polymorphism analysis in the rapid authentication of Radix astragali. J Agric Food Chem 2005; 53: 8551-6

103 Cheng KT, Su B, Chen CT, Lin CC. RAPD analysis of Astragalus medicines marketed in Taiwan. Am J Chin Med 2000; 28: 273-8

104 Ma XQ Duan JA, Zhu DY, Dong TT, Tsim KW. Species identification of Radix Astragali (Huangqi) by DNA sequence of its 5S-rRNA spacer domain. Phytochemistry 2000; 54: $363-8$

105 Yip PY, Kwan HS. Molecular identification of Astragalus membranaceus at the species and locality levels. J Ethnopharmacol 2006; 106: 222 -9

106 Zhang X, Xu Q Xiao H, Liang X, Huang L, Liu J. Study on authentication of Astragalus membranaceus by DNA fingerprints. World Science And Technology/Modernization of Tradtitional Chinese Medicine and Materia Medica 2006; 8: 33-6 
107 Zhao KJ, Dong TT, Tu PF, Song ZH, Lo CK, Tsim KW. Molecular genetic and chemical assessment of Radix Angelica (Danggui) in China. J Agric Food Chem 2003; 51: 2576-83

108 Xia Q, Zhao KJ, Huang ZG, Zhang P, Dong TT, Li SP et al. Molecular genetic and chemical assessment of Rhizoma Curcumae in China. J Agric Food Chem 2005; 53: 6019- 26

109 Zhang YB, Ngan FN, Wang ZT, Ng TB, But PP, Shaw PC et al. Random primed polymerase chain reaction differentiates Codonopsis pilosula from different localities. Planta Med 1999; 65: 157-60

110 Ma XQ Shi Q Duan JA, Dong TT, Tsim KW. Chemical analysis of Radix Astragali (Huangqi) in China: a comparison with its adulterants and seasonal variations. J Agric Food Chem 2002; 50: 4861 -6

111 Hamburger M, Hostettmann K. 7. Bioactivity in plants: the link between phytochemistry and medicine. Phytochemistry 1991; 30: $3864-74$

112 Briskin DP. Medicinal plants and phytomedicines. Linking plant biochemistry and physiology to human health. Plant Physiol 2000; 124: 507-14

113 Holmes E, Tang H, Wang $Y$, Seger $C$. The assessment of plant metabolite profiles by NMR-based methodologies. Planta Med 2006; 72: $771-85$

114 Saiki RK, Chang CA, Levenson CH, Warren TC, Boehm CD, Kazazian HH Jr et al. Diagnosis of sickle cell anemia and beta-thalassemia with enzymatically amplified DNA and nonradioactive allele-specific oligonucleotide probes. N Engl J Med 1988; 319: 537-41

115 Saiki RK, Scharf S, Faloona F, Mullis KB, Horn GT, Erlich HA et al. Enzymatic amplification of beta-globin genomic sequences and restriction site analysis for diagnosis of sickle cell anemia. Science 1985; 230: $1350-4$

116 Dieffenbach C, Dveksler G. PCR primer: A laboratory manual, 2nd edition. Cold Spring Harbor, NY: Cold Spring Harbor Laboratory Press; 2003: 520

117 Gupta PK, Roy JK, Prasad M. Single nucleotide polymorphisms: A new paradigm for molecular marker technology and DNA polymorphism detection with emphasis on their use in plants. Curr Sci 2001; 80: $524-35$

118 Newton CR, Graham A, Heptinstall LE, Powell SJ, Summers C, Kalsheker $N$ et al. Analysis of any point mutation in DNA. The amplification refractory mutation system (ARMS). Nucleic Acids Res 1989; 17: $2503-16$

119 Vos P, Hogers R, Bleeker M, Reijans $M$, van de Lee T, Hornes $M$ et al. AFLP: a new technique for DNA fingerprinting. Nucleic Acids Res 1995; 23: $4407-14$

120 Desmarais E, Lanneluc I, Lagnel J. Direct amplification of length polymorphisms (DALP), or how to get and characterize new genetic markers in many species. Nucleic Acids Res 1998; 26: 1458 - 65

121 Lin J, Zhou X, Gao S, Wu W, Liu X, Sun X et al. Authentication of Pinellia ternata and its adulterants based on PCR with specific primers. Planta Med 2006; 72: 844-7

122 Paran I, Michelmore RW. Development of reliable PCR-based markers linked to downy mildew resistance genes in lettuce. Theor Appl Genet 1993; 85: $985-93$

123 Schena M, Heller RA, Theriault TP, Konrad K, Lachenmeier E, Davis RW. Microarrays: biotechnology's discovery platform for functional genomics. Trends Biotechnol 1998; 16: $301-6$

124 Kretz K, Callen W, Hedden V. Cycle sequencing. PCR Methods Appl 1994; 3: S107-12

125 Zietkiewicz E, Rafalski A, Labuda D. Genome fingerprinting by simple sequence repeat (SSR)-anchored polymerase chain reaction amplification. Genomics 1994; 20: 176-83

126 Fortina P, Dotti G, Conant R, Monokian G, Parrella T, Hitchcock W et al. Detection of the most common mutations causing beta-thalassemia in Mediterraneans using a multiplex amplification refractory mutation system (MARMS). PCR Methods Appl 1992; 2: 163 - 6

127 Weber JL, May PE. Abundant class of human DNA polymorphisms which can be typed using the polymerase chain reaction. Am J Hum Genet 1989; 44: 388 - 96

128 Kuzoff RK, Sweere JA, Soltis DE, Soltis PS, Zimmer EA. The phylogenetic potential of entire 26S rDNA sequences in plants. Mol Biol Evol 1998; 15: $251-63$

129 Wendel JF, Álvarez I. Ribosomal ITS sequences and plant phylogenetic inference. Mol Phylogenet Evol 2003; 29: 417-34

130 Sugiura M. The chloroplast genome. Plant Mol Biol 1992; 19: 149-68
131 Liu X, Xu H, Huang C. Chloroplast chlB gene is required for light-independent chlorophyll accumulation in Chlamydomonas reinhardtii. Plant Mol Biol 1993; 23: 297 - 308

132 Heubl G, Bringman G, Meimberg H. Molecular phylogeny and character evolution of carnivours plant families in caryophyllales - revisited. Plant Biol 2006; 8: 821-30

133 Chase MW, Salamin N, Wilkinson M, Dunwell JM, Kesanakurthi RP, Haidar $N$ et al. Land plants and DNA barcodes: short-term and longterm goals. Philos Trans R Soc Lond Ser B Biol Sci 2005; 360: 188995

134 Zerega NJC, Mori S, Lindqvist C, Zheng Q, Motley TJ. Using amplified fragment length polymorphisms (AFLP) to identify black cohosh (Actaea racemosa). Econ Bot 2002; 56: $154-64$

135 Zhao KJ, Dong TT, Cui XM, Tu PF, Tsim KW. Genetic distinction of radix adenophorae from its adulterants by the DNA sequence of 5S-rRNA spacer domains. Am J Chin Med 2003; 31: 919-26

136 Luo JP, Cao H, Liu YP. [DNA sequencing and molecular identification of Patchouli and its substitute wrinkled gianthyssop]. Yao Xue Xue Bao 2002; 37: 739 - 42

137 Li X, Ding X, Chu B, Ding G, Gu S, Qian L et al. Molecular authentication of Alisma orientale by PCR-RFLP and ARMS. Planta Med 2007; 73: $67-70$

138 Hosokawa K, Hishida A, Nakamura I, Shibata T. The sequences of the spacer region between the atpF and atpA genes in the plastid genome allows discrimination among three varieties of medicinal Angelica. Planta Med 2006; 72: 570-1

139 Watanabe A, Araki S, Kobari S, Sudo H, Tsuchida T, Uno T et al. In vitro proagation, restriction fragment length polymorphism, and random ampliefied polymorphic DNA analyses of Angelica plants. Plant Cell Rep 1998; 18: 187-92

140 Lee MY, Doh EJ, Park CH, Kim YH, Kim ES, Ko BS et al. Development of SCAR marker for discrimination of Artemisia princeps and A. argyi from other Artemisia herbs. Biol Pharm Bull 2006; 29: 629 - 33

141 Kelly LM. Phylogenetic relationships in Asarum (Aristolochiaceae) based on morphology and ITS sequences. Am J Bot 1998; 85: $1454-$ 67

142 Liu CS, Bai GB, Yan YN. [Studies on the botanical sources and DNA molecular identification of Herba Asari based on ITS sequence] Zhongguo Zhong Yao Za Zhi 2005; 30: 329- 32

143 Guo Y, Kondo K, Terabayashi S, Yamamoto Y, Shimada H, Fujita M et al. DNA authentication of So-jutsu (Atractylodes lancea rhizome) and Byaku-jutsu (Atractylodes rhizome) obtained in the market based on the nucleotide sequence of the 18S-5.8S rDNA internal transcribed spacer region. J Nat Med 2006; 60: 149-56

144 Chen K-T, Su Y-C, Lin J-G, SHsin L-H, Su Y-P, Su C-H et al. Identification of Atractylodes plants in Chinese herbs and formulations by random amplified plymorphic DNA. Acta Pharmacol Sin 2001; 22: $493-7$

145 Darokar MP, Khanuja SPS, Shasany AK, Kumar S. Low levels of genetic diversity detected by RAPD analysis in geographically distinct accessions of Bacopa monnieri. Genet Resour Crop Evol 2001; 48: 555 -8

146 Yang ZY, Chao Z, Huo KK, Xie H, Tian ZP, Pan SL. ITS sequence analysis used for molecular identification of the Bupleurum species from northwestern China. Phytomedicine 2007; 14: 416-23

147 Ma XQ Zhu DY, Li SP, Dong TT, Tsim KW. Authentic identification of stigma Croci (stigma of Crocus sativus) from its adulterants by molecular genetic analysis. Planta Med 2001; 67: 183-6

$148 \mathrm{Fu}$ C, Qiu Y, Kong H. RAPD analysis for genetic diversity in Changium smyrnioides (Apiaceae), an endangered plant. Bot Bull Acad Sin 2003; 44: $13-8$

149 Nebauer SG, Castillo-Agudo Ld, Segura J. RAPD variation within and among natural populations of outcrossing willow-leave foxglove (Digitalis obscura L.). Theor Appl Genet 1999; 98: 985 - 94

150 Liu Y-p, He B-z, Cao H. Application of gene technology in quality control of Chinese drugs (II) - Identification of Chinese yam (Dioscorea polystachia rhizome) using DNA sequencing. Chin J Tradit Herb Drugs 2001; 32: $113-7$

151 Gong W, Fu C-X, Luo Y-P, Qiu Y-X. Molecular identification of Sinopodophyllum hexandrum and Dysosma species using cpDNA sequences and PCR-RFLP markers. Planta Med 2006; 72: 650-2

152 Kapteyn J, Goldsbrough PB, Simon JE. Genetic relationships and diversity of commercially relevant Echinacea species. Theor Appl Genet 2002; 105: 369-76

153 Zhang Y, Liu W, Ai T. DNA molecular identification of the three Echinacea species. Chin J Information on Tradit Chin Med 2002; 9: 11-2 
154 Sun Y, Fung KP, Leung PC, Shi D, Shaw PC. Characterization of medicinal Epimedium species by $5 \mathrm{~S}$ rRNA gene spacer sequencing. Planta Med 2004; 70: 287 -8

155 Xue HG, Zhou SD, He XJ, Yu Y. Molecular authentication of the traditional Chinese medicinal plant Euphorbia pekinensis. Planta Med 2007; 73: $91-3$

156 Xue CY, Li DZ, Lu JM, Yang JB, Liu JQ. Molecular authentication of the traditional Tibetan medicinal plant Swertia mussotii. Planta Med 2006; 72: $1223-6$

157 Mizukami H, Ohbayashi K, Umetsu K, Hiraoka N. Restriction fragment length polymorphism of medicinal plants and crude drugs. II. Analysis of Glehnia littoralis of different geographical origin. Biol Pharm Bull 1993; 16: $611-2$

158 Yang ZY, Chao Z, Huo KK, Wu BY, Pan SL. [Nuclear ribosomal DNA internal transcribed spacer 1 sequences of 4 Leonurus species]. Nan Fang Yi Ke Da Xue Xue Bao 2006; 26: 1593 - 5

159 Zhang M, Zhang DZ, Xu XH, Zhang T, Wang ZT. 5S rRNA gene spacer sequences from Ligularia medicinal plants and the identification of HPAs-containing species. Chin J Nat Med 2005; 3: 38 - 40

160 Zhang KY, Leung HW, Yeung HW, Wong RN. Differentiation of Lycium barbarum from its related Lycium species using random amplified polymorphic DNA. Planta Med 2001; 67: 379-81

161 Lum MR, Potter E, Dang T, Heber D, Hardy M, Hirsch AM. Identification of botanicals and potential contaminants through RFLP and sequencing. Planta Med 2005; 71: $841-6$

162 Wang J, Ha WY, Ngan FN, But PP, Shaw PC. Application of sequence characterized amplified region (SCAR) analysis to authenticate Panax species and their adulterants. Planta Med 2001; 67: 781-3

163 Hon CC, Chow YC, Zeng FY, Leung FC. Genetic authentication of ginseng and other traditional Chinese medicine. Acta Pharmacol Sin 2003; $24: 841-6$

164 Luo YM, Zhang WM, Ding XY, Shen J, Bao SL, Chu BH et al. SNP marker and allele-specific diagnostic PCR for authenticating herbs of Perilla. Acta Pharm Sin 2006; 41: 840-5

165 Lee SK, Li PT, Lau DT, Yung PP, Kong RY, Fong WF. Phylogeny of medicinal Phyllanthus species in China based on nuclear ITS and chloroplast atpB-rbcL sequences and multiplex PCR detection assay analysis. Planta Med 2006; 72: 721-6

166 Dnyaneshwar W, Preeti C, Kalpana J, Bhushan P. Development and application of RAPD-SCAR marker for identification of Phyllanthus emblica LINN. Biol Pharm Bull 2006; 29: 2313 -6

167 Liu Y-p, Cao H, Wang X-t. Application of gene technology in quality control of Chinese drugs(I) - identification of Pinellia ternata species from Yuncheng, Shandong using DNA sequencing. Chin J Pharm Anal 2001; 21: 423-6

168 Yang J, Zhu X, Luo C. RAPD analysis on the germplasm resources of Pinellia ternata. Chin J Information on Tradit Chin Med 2007; 14: $42-5$

169 Das M, Raychaudhuri SS. Estimation of genetic variability in Plantago ovata cultivars. Biol Plant 2003/4; 47: 459-62

170 Passinho-Soares H, Felix D, Kaplan MA, Margis-Pinheiro M, Margis R. Authentication of medicinal plant botanical identity by amplified fragmented length polymorphism dominant DNA marker: inferences from the Plectranthus genus. Planta Med 2006; 72: 929-31

171 Sun Y, Shaw PC, Fung KP. Molecular authentication of Radix Puerariae Lobatae and Radix Puerariae Thomsonii by ITS and 5S rRNA spacer sequencing. Biol Pharm Bull 2007; 30: 173-5

172 Yang $M$, Zhang D, Liu J, Zheng J. A molecular marker that is specific to medicinal rhubarb based on chloroplast trnL/trnF sequences. Planta Med 2001; 67: 784-6

173 Xia T, Chen S, Chen S, Zhang D, Zhang D, Gao Q et al. ISSR analysis of genetic diversity of the Qinghai-Tibet plateau endemic Rhodiola chrysanthemifolia (Crassulaceae). Biochem Syst Ecol 2007; 35: 209- 14

174 Wang H, Wang Q. Analysis of rDNA ITS sequences of Radix et Rhozoma Salviae miltiorrhizae and plants of Salvia L. Chin Tradit Herb Drugs 2005; 36: $1381-5$

175 Hosokawa K, Minami M, Nakamura I, Hishida A, Shibata T. The sequences of the plastid gene rpl16 and ther rpl16-rpl14 spacer region allow discrimination among six species of Scutellaria. J Ethnopharmacol 2005; 99: $105-8$

176 Shao A-J, Li X, Huang L-Q Lin S-F, Chen J. RAPD analysis of Scutellaria baicalensis from different germplasms. China J Chin Mater Med 2006; 31: $452-5$

177 Hosokawa K, Minami M, Kawahara K, Nakamura I, Shibata T. Discrimination among three species of medicinal Scutellaria plants using RAPD markers. Planta Med 2000; 66: 270-2

178 Echeverrigaray S, Agostini G, Atti-Serfini L, Paroul N, Pauletti GF, dos Santos AC. Correlation between the chemical and genetic relationships among commercial thyme cultivars. J Agric Food Chem 2001; 49: $4220-3$

179 Rout GR. Identification of Tinospora cordifolia (Willd.) Miers ex Hook F \& Thomas using RAPD markers. Z Naturforsch [C] 2006; 61: 118 22 